\title{
Barriers to the Wider Use of Pre-exposure Prophylaxis in the United States: A Narrative Review
}

\author{
Kenneth H. Mayer · Allison Agwu · David Malebranche
}

Received: January 30, 2020 / Published online: March 30, 2020

(C) The Author(s)

\begin{abstract}
Antiretroviral pre-exposure prophylaxis (PrEP) to prevent HIV transmission was first approved by the US Food and Drug Administration in 2012. Despite correlations of decreases in new HIV infections being greatest where PrEP has been deployed, the uptake of PrEP is lagging, particularly among populations with disproportionate HIV burden. This narrative review seeks to identify individual and systemic barriers to PrEP usage in the USA. A comprehensive search of recent literature uncovered a complex array of structural, social, clinical, and behavioral barriers, including knowledge/awareness of PrEP, perception of HIV risk, stigma from healthcare providers or family/partners/friends, distrust of healthcare providers/systems, access to PrEP, costs of PrEP, and concerns around PrEP
\end{abstract}

Enhanced Digital Features To view enhanced digital features for this article go to https://doi.org/10.6084/ m9.figshare.11961357.

K. H. Mayer ( $\square)$

The Fenway Institute and Harvard Medical School, Boston, MA, USA

e-mail: khmayer@gmail.com

\section{A. Agwu}

Johns Hopkins University School of Medicine,

Baltimore, MD, USA

D. Malebranche

Morehouse School of Medicine, Atlanta, GA, USA side effects/medication interactions. Importantly, these barriers may have different effects on specific populations at risk. The full potential of PrEP for HIV prevention will not be realized until these issues are addressed. Strategies to achieve this goal should include educational interventions, innovative approaches to delivery of HIV care, financial support, and destigmatization of PrEP and PrEP users. Until then, PrEP uptake will continue to be suboptimal, particularly among those who need it most.

\section{PLAIN LANGUAGE SUMMARY}

Pre-exposure prophylaxis (PrEP) is a way of preventing HIV. By taking a daily pill, which contains two medicines, HIV can be stopped before it causes an infection. PrEP is prescribed for people at risk of HIV infection. However, many people who are at risk do not use PrEP. We explored the reasons for this. We found that many individuals at risk had not heard of PrEP, so would be unable to ask their doctors for it. Even among healthcare providers themselves, some were not aware of PrEP or how it should be used. For individuals who have heard of PrEP, unfortunately a stigma remains around HIV that deters some people from seeking the treatment. Furthermore, many individuals at 
risk have experienced bias at the hands of healthcare providers, deepening distrust of the medical establishment. Many individuals at risk also experience poverty and although there are multiple financial assistance options for PrEP, these can be difficult to access without support. Public education and training of healthcare providers may address many of the barriers we found, but deep-rooted issues such as racism and bias will require significant changes within the healthcare system.

Keywords: Access; Barriers; Distrust; Emtricitabine; Implementation; Prevention; Pre-exposure prophylaxis; Stigma; Tenofovir alafenamide; Tenofovir disoproxil fumarate

\section{Key Summary Points}

Antiretroviral pre-exposure prophylaxis (PrEP) reduces HIV transmission, but barriers to PrEP access limit uptake in the USA.

Awareness of PrEP remains low in populations at risk and is inadequate in some healthcare provider settings, requiring educational initiatives.

Low perception of HIV risk among individuals and healthcare providers limits PrEP uptake, alongside lack of access to appropriate, unbiased medical care.

Financial and social stigma barriers also reduce PrEP uptake, although legal changes to PrEP coverage by insurance providers and social media interventions may provide opportunities to overcome these barriers.

\section{INTRODUCTION}

The antiretroviral combination of emtricitabine and tenofovir disoproxil fumarate $\left(\right.$ Truvada $^{\circledR}$;
F/TDF) was the first medication approved by the US Food and Drug Administration in 2012 for use as HIV pre-exposure prophylaxis (PrEP) to prevent HIV acquisition, based on several pivotal trials [1-3]. Since then, PrEP medications have been shown to be effective at preventing HIV transmission in those at greatest risk of acquisition. A retrospective analysis of the National HIV Surveillance System and national pharmacy data showed an independent and significant association between F/TDF PrEP use and a decline in the number of new HIV infections diagnosed in the USA from 2012 to 2016 in communities where it was most widely used [4]. Over this period, PrEP use increased from 7.0 to 68.5 per 1000 persons for whom it was indicated (estimated annual percent change $(\mathrm{EAPC})+78.0$, confidence interval $(\mathrm{CI})+77.3$, $78.7 \%$ ), while the rate of new HIV diagnoses among the general population decreased significantly from 15.7 to 14.5 per 100,000 persons (EAPC - 1.6, CI - 1.9, - 1.3). In states with the highest PrEP use $(11 \%$ average prevalence among individuals for whom PrEP is indicated), the pooled EAPC of HIV diagnoses was $-4.7 \%$, whereas the EAPC of HIV diagnoses was $+0.9 \%$ in states with the lowest PrEP use (3\% average prevalence among PrEP-indicated individuals). The observed association of PrEP with decreasing HIV incidence remained significant after controlling for state-specific levels of viral suppression among HIV-positive individuals.

Despite the effectiveness of PrEP in the prevention of HIV transmission, there remain challenges, reflected by low levels of utilization in the USA. As of the third quarter of 2019, an estimated 224,000 people in the USA received a prescription for HIV PrEP (Gilead Sciences, data on file), a fraction of the 1.1 million Americans estimated to have indications for PrEP (data as of 2015) [5, 6]. The lack of uptake is especially low among populations disproportionately affected by HIV.

For example, Black and Latinx individuals (who represented 69\% of new HIV diagnoses in 2017) comprised only 24\% of PrEP users in 2016 $[7,8]$. PrEP uptake may also be insufficient in people who inject drugs (PWID). A survey of primary care physicians showed over one-quarter had low willingness to prescribe PrEP to 
PWID, despite some PWIDs having a substantial risk for HIV acquisition [9]. Cisgender women at risk of HIV also have relatively low PrEP uptake. Based on available commercial US pharmacy data, the EAPC between 2012 and 2017 was a $5 \%$ increase for women starting PrEP, compared with a $68 \%$ increase among men [5]. Furthermore, a Centers for Disease Control (CDC) analysis of 2016 prescription data found that only $2 \%$ of women for whom PrEP was indicated were using it [7]. This reflects an inequality in PrEP use for women relative to their need, since more than a quarter of new HIV infections (in 2016) occurred in women [5].

Age may be a factor in PrEP uptake; young individuals at risk have lower levels of PrEP use relative to their need $[10,11]$. In an analysis of 2017 prescription-level data, PrEP use in those under 24 years of age was 15.2 per 100,000 persons, with a PrEP-to-need ratio (PnR; ratio of PrEP users to new HIV diagnoses) of 0.9. In comparison, among those aged 24-35 years, PrEP use was 61.5 per 100,000 persons, and the PnR was 2.0 [11]. Finally, geography may also contribute to disparity in rates of PrEP use. For instance, although men and women in the South accounted for $52 \%$ of US HIV diagnoses in 2017, only $27 \%$ of PrEP users were in the South (from 2016 data) $[7,12]$.

Importantly, there appears to be a mismatch between individual risk/risk perception and PrEP uptake. A Seattle survey of men who have sex with men (MSM) and transgender individuals (men and women) who have sex with men showed that only $3 \%$ of participants had ever used PrEP, despite nearly all having heard of PrEP and having health insurance [13]. Similarly, in a 2019 survey of transgender men, although $55.2 \%$ of respondents had an indication for PrEP, only $21.8 \%$ reported current PrEP use [14]. Additionally, an analysis of over 400 MSM in Los Angeles demonstrated that knowledge of PrEP increased from 39\% to $82 \%$ from 2011 to 2014, but actual PrEP use rose from no use to only $8 \%$ across the same period $[15,16]$.

In summary, poor PrEP uptake among individuals for whom it is indicated is a substantial problem in the USA, affecting diverse groups. Understanding barriers to PrEP use is paramount in ensuring its effective implementation, particularly among populations with disproportionate and/or increasing rates of HIV acquisition. In this narrative review, we aim to assess and characterize barriers to PrEP use in the USA. We will examine barriers for both individuals at risk and providers, exploring which barriers are common to most populations and which are highlighted in specific populations.

\section{SEARCHES}

We assessed peer-reviewed papers and conference abstracts to identify barriers to PrEP uptake in the USA among those at risk for HIV by searching PubMed, International AIDS Conference 2019, and Conference on Retroviruses and Opportunistic Infections 2019 abstracts, using the terms "PrEP OR pre-exposure prophylaxis OR pre-exposure prophylaxis" AND "HIV" AND "clinical trial OR classical article OR clinical study OR comparative study OR meta-analysis OR multicenter study OR observational study OR qualitative research OR barriers". As this field is rapidly evolving, we focused on articles from 2016 onwards. Key themes were identified from the initial search: knowledge/awareness of PrEP; perception of HIV risk; social stigma; provider bias and distrust of healthcare providers/systems; lack of access to medical care; lack of access to (or awareness of) financial assistance options; and PrEP side effects and medication interaction concerns (Table 1). Each of the identified barrier categories was reviewed with consideration of individual behavioral and sociodemographic factors, as well as healthcare provider/systemic factors. Other relevant references were identified for each category either from the bibliography of original articles or by carrying out additional PubMed searches during manuscript development on "PrEP OR preexposure prophylaxis OR pre-exposure prophylaxis" AND "HIV" AND (knowledge OR 
Table 1 Summary of key barriers to PrEP uptake as identified in the recent literature and potential approaches to removing barriers to PrEP

\begin{tabular}{ll}
\hline Key barriers & Potential approaches to removing barriers \\
\hline Awareness of PrEP & Patient and provider education \\
& Better communication between providers \\
HIV risk perception & Patient and provider education \\
Stigma & Improved cultural humility (via education and advocacy) \\
& Improved communication and understanding between patient and provider \\
Provider bias and distrust of & Patient and provider education \\
healthcare system & Addressing systemic entrenched bias (via education, advocacy, and recruitment of more \\
& Black, Latinx, and LGBTQ healthcare professionals) \\
Access to medical care & Patient and provider education \\
& Extending access to PrEP (e.g., substance use clinics, emergency rooms, pharmacies, \\
& correctional institutions, etc.) \\
Leveraging technology to improve access (e.g., telemedicine) & Addressing competing priorities (e.g., food, shelter, safety, other healthcare, childcare) \\
Lack of access to financial & Help for patients in navigating financial aid options \\
assistance & Patient and provider education
\end{tabular}

$H I V$ human immunodeficiency virus, $L G B T Q$ lesbian, gay, bisexual, transgender, and queer, $\operatorname{PrEP}$ pre-exposure prophylaxis

awareness OR risk perception OR stigma OR bias OR distrust OR access OR cost OR side effects OR interaction). This article is based on previously conducted studies and does not contain any studies with human participants or animals performed by any of the authors.

\section{AWARENESS AND KNOWLEDGE AS A BARRIER TO PREP UPTAKE}

Before any other factors influencing PrEP uptake come into play, both individuals at risk and healthcare providers need to be aware of the existence of PrEP as a preventive option. Nationally, in the general population, awareness of PrEP is low. In a survey of 19,806 adults in the USA (general public) between 2009 and
2014, only 6.5\% reported awareness of PrEP [17]. More recent national data are not available, but smaller studies suggest that general awareness remains low. A 2018 study of the North Carolina general public $(N=409)$ found that only 9\% had heard of PrEP [18]; a 2018 Southern Arizona study $(N=500)$ noted that only $20 \%$ of individuals surveyed at public health department clinics (which provided family planning and sexually transmitted infection testing/treatment) were aware of PrEP [19].

In populations at high risk for HIV acquisition, PrEP awareness varies and study findings are often contradictory. For example, relatively high knowledge/awareness of PrEP among racially and ethnically diverse populations of MSM, transgender women, and transgender 


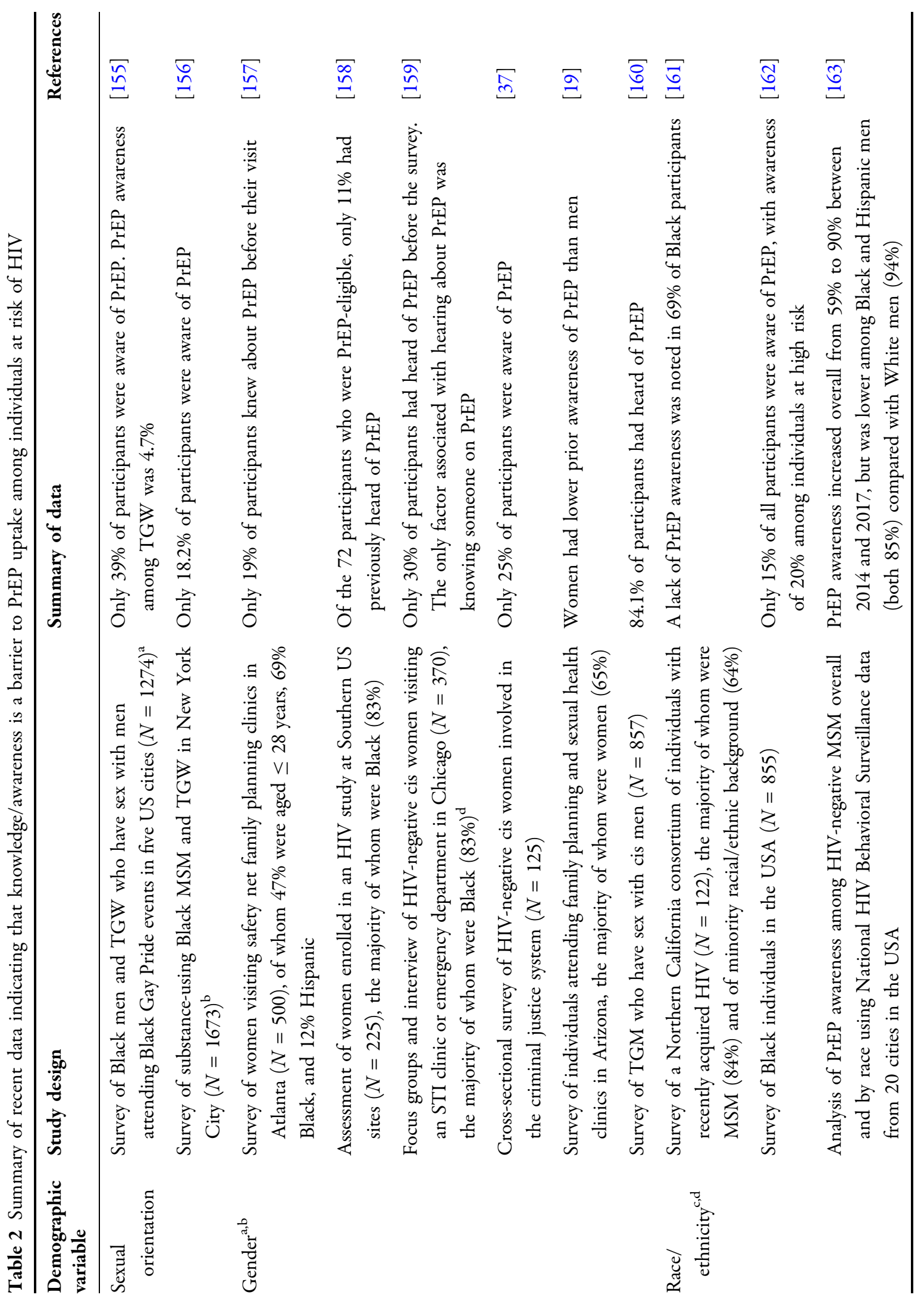




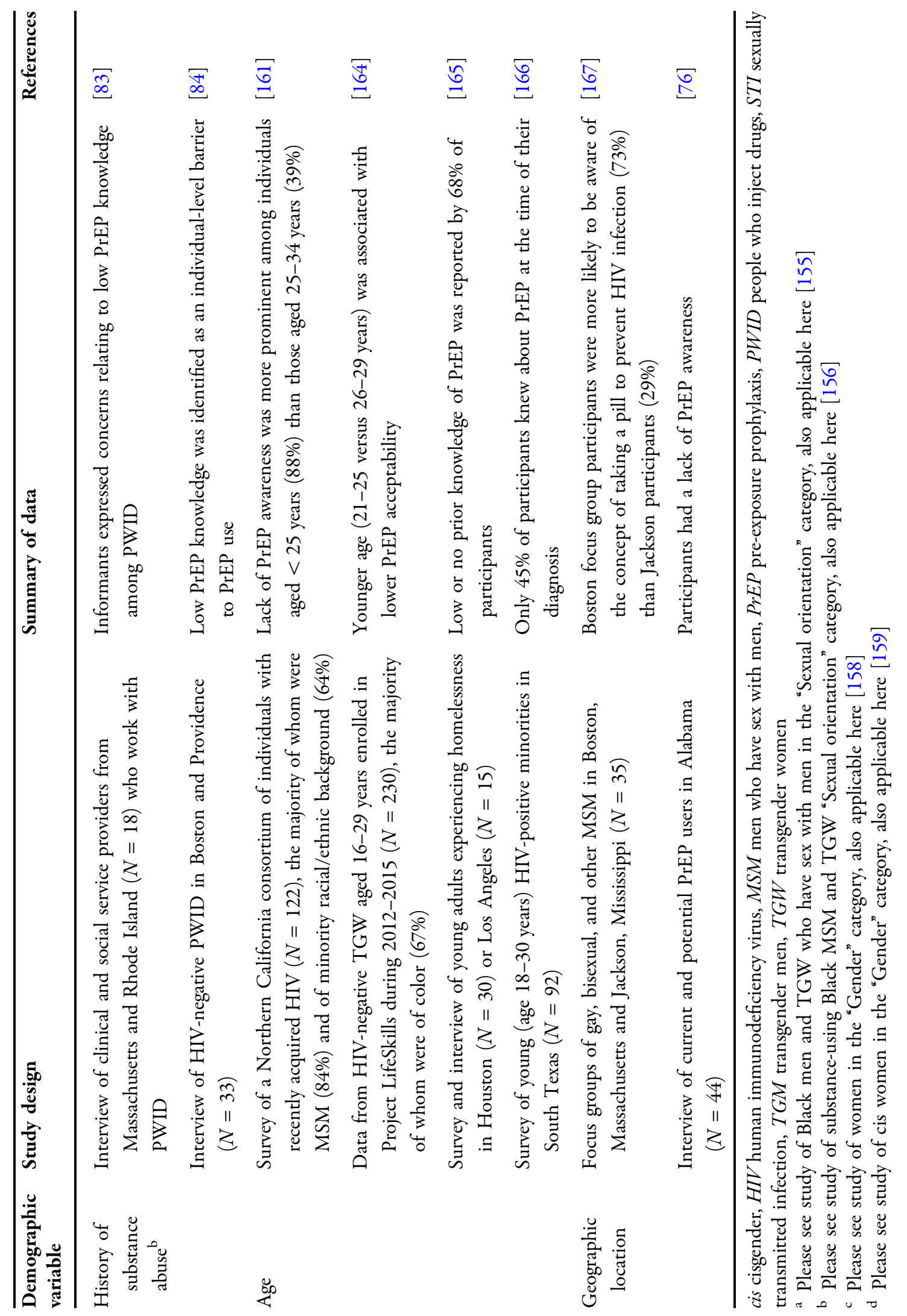


Table 3 Summary of recent studies about PrEP awareness and knowledge among healthcare professionals/providers

\begin{tabular}{|c|c|c|c|}
\hline Study participants & Study methods & Summary of key data & References \\
\hline US nurse practitioners $(N=271)$ & $\begin{array}{l}\text { Cross-sectional survey of American } \\
\text { annual conference attendees; } \\
\text { presented in } 2019\end{array}$ & $\begin{array}{l}\text { 60.1\% reported no prior PrEP } \\
\text { training or education; } 62.4 \% \\
\text { reported never starting a } \\
\text { conversation about PrEP; Half } \\
\text { reported being "confident" in } \\
\text { discussing PrEP with an } \\
\text { individual, monitoring PrEP side } \\
\text { effects, or testing PrEP patients } \\
\text { for HIV }\end{array}$ & {$[25]$} \\
\hline $\begin{array}{l}\text { Physicians (adolescent } \\
\text { medicine/family practice/ } \\
\text { internal medicine/pediatrics/ } \\
\text { obstetrics and gynecology) } \\
\text { providing primary care to } \\
\text { adolescents aged 13-21 years } \\
(N=38)\end{array}$ & $\begin{array}{l}\text { Individual, in-depth, semi- } \\
\text { structured interviews }\end{array}$ & $\begin{array}{l}\text { 37\% reported being somewhat or } \\
\text { very familiar with PrEP; } \\
\text { perceived benefits of prescribing } \\
\text { PrEP included decreased HIV } \\
\text { acquisition, and improved } \\
\text { awareness of HIV risk among } \\
\text { recipients }\end{array}$ & {$[31]$} \\
\hline $\begin{array}{l}\text { Internal medicine trainees at a } \\
\text { medium-sized internal medicine } \\
\text { program }(N=48)\end{array}$ & $\begin{array}{l}\text { PrEP-focused educational } \\
\text { intervention with pre- } \\
\text { intervention and post- } \\
\text { intervention surveys }\end{array}$ & $\begin{array}{l}\text { Pre-intervention: } 22 \% \text { of trainees } \\
\text { were unaware of PrEP, } 78 \% \\
\text { believed PrEP was effective, } 66 \% \\
\text { believed it was safe, and } 62 \% \text { had } \\
\text { fair/poor awareness of side } \\
\text { effects } \\
\text { Post-intervention: } 94 \% \text { believed } \\
\text { PrEP was effective and } 92 \% \\
\text { believed PrEP was safe }\end{array}$ & {$[98]$} \\
\hline $\begin{array}{l}\text { Clinical and social service } \\
\text { providers who work with PWID } \\
\text { in small cities and towns in } \\
\text { Massachusetts and Rhode Island } \\
(N=18)\end{array}$ & $\begin{array}{l}\text { Semi-structured qualitative } \\
\text { interviews; presented in } 2019\end{array}$ & $\begin{array}{l}\text { Interviewees viewed PrEP as a } \\
\text { promising but underutilized } \\
\text { HIV prevention strategy. } \\
\text { Interviewees also reported } \\
\text { limited confidence among staff } \\
\text { delivering PrEP }\end{array}$ & [83] \\
\hline $\begin{array}{l}\text { First-year health professions } \\
\text { students and interdisciplinary } \\
\text { care teams at a health } \\
\text { department in Illinois }(N=11)\end{array}$ & $\begin{array}{l}\text { Mixed-methodology assessment of } \\
\text { a service-learning project to } \\
\text { compile a training module (by } \\
\text { health professions students), } \\
\text { presented to interdisciplinary } \\
\text { care teams }\end{array}$ & $\begin{array}{l}\text { Students and care teams } \\
\text { underinformed about PrEP had } \\
\text { self-reported increased awareness } \\
\text { and confidence in identifying } \\
\text { individuals at risk for HIV } \\
\text { infection after training } \\
\text { intervention }\end{array}$ & {$[168]$} \\
\hline
\end{tabular}


Table 3 continued

\begin{tabular}{llll}
\hline Study participants & Study methods & Summary of key data & References \\
\hline Healthcare providers (including & 25-item questionnaire, conducted & $66.7 \%$ correctly defined PrEP; & {$[26]$} \\
infectious disease consultants, & between January and March & $58.3 \%$ had read the CDC's PrEP & \\
family/general practitioners, & 2017 & clinical practice guidelines; & \\
obstetrics/gynecology specialists, & & $41.7 \%$ were able to correctly & \\
internist, and physician assistant) & & identify PrEP prescribing & \\
in Florida $(N=12)$ & & recommendations & \\
\hline
\end{tabular}

$C D C$ Centers for Disease Control, $H I V$ human immunodeficiency virus, $\operatorname{PrEP}$ pre-exposure prophylaxis, $P W I D$ people who inject drugs

men was noted in some studies (Table 2), while others suggest low awareness in these populations (Table 2). However, several studies have more consistently demonstrated lack of awareness of PrEP among other populations at risk of HIV acquisition, including Black MSM, PWID, younger individuals, and communities in the Deep South (Table 2). Even among individuals aware of PrEP, limited knowledge about PrEP (i.e., if they have questions or concerns about it) can prevent PrEP initiation [20].

Lack of PrEP awareness has also been observed among people living with HIV, as was reported for $66 \%$ of participants $(N=137)$ surveyed in a Miami public hospital [21]. This is concerning, as these people living with HIV would be unable to advise their partners about PrEP [21]. In that same study, once they knew about PrEP, $86.0 \%$ of respondents reported that they would encourage their partners to use it [21].

Knowledge and awareness of PrEP among healthcare providers are also crucial for successful implementation [22] and can directly impact prescribing rates. In a study of local health departments in North Carolina, lack of PrEP awareness and knowledge among health department staff was cited as one of the most common reasons for not prescribing or referring individuals for PrEP [23].

While one 2018 study of New Jersey healthcare workers (including administrators, prescribers, social workers, and nurses) demonstrated a high level of PrEP awareness, at 91\% [24], other studies suggest inadequate knowledge or awareness among some healthcare professionals/providers (Table 3). For example, $60 \%$ of 271 US nurse practitioners reported no prior PrEP training or education [25], while $58.3 \%$ of 12 Florida healthcare providers had read the CDC's PrEP clinical practice guidelines, and only $41.7 \%$ could identify correct PrEP prescribing recommendations [26].

There are clear differences in awareness and knowledge within the healthcare professions. Only $65 \%$ of licensed medical providers surveyed in Washington State in $2016(N=735)$ had heard of PrEP, with younger healthcare professionals and those with a medical degree more likely to be aware of PrEP than older healthcare professionals and those with other training backgrounds [27]. There was also a disparity in awareness according to specialty; all infectious disease specialists surveyed had heard of PrEP, compared with around three-quarters of board-certified family medicine and internal medicine practitioners and around half of obstetrics/gynecology and pediatric practitioners [27]. Similarly, in a study of 53 family physicians, $71 \%$ had no/limited knowledge of PrEP treatment guidelines [28].

This disparity in awareness and knowledge between different healthcare professionals is important when considering the setting in which PrEP should be prescribed. Primary care doctors and generalists often consider PrEP to be an issue for HIV specialists $[29,30]$. However, while infectious diseases specialists have knowledge of PrEP and the most experience in HIV care, they usually do not provide care for HIV-negative individuals who may benefit from PrEP; in fact, primary care physicians are more 


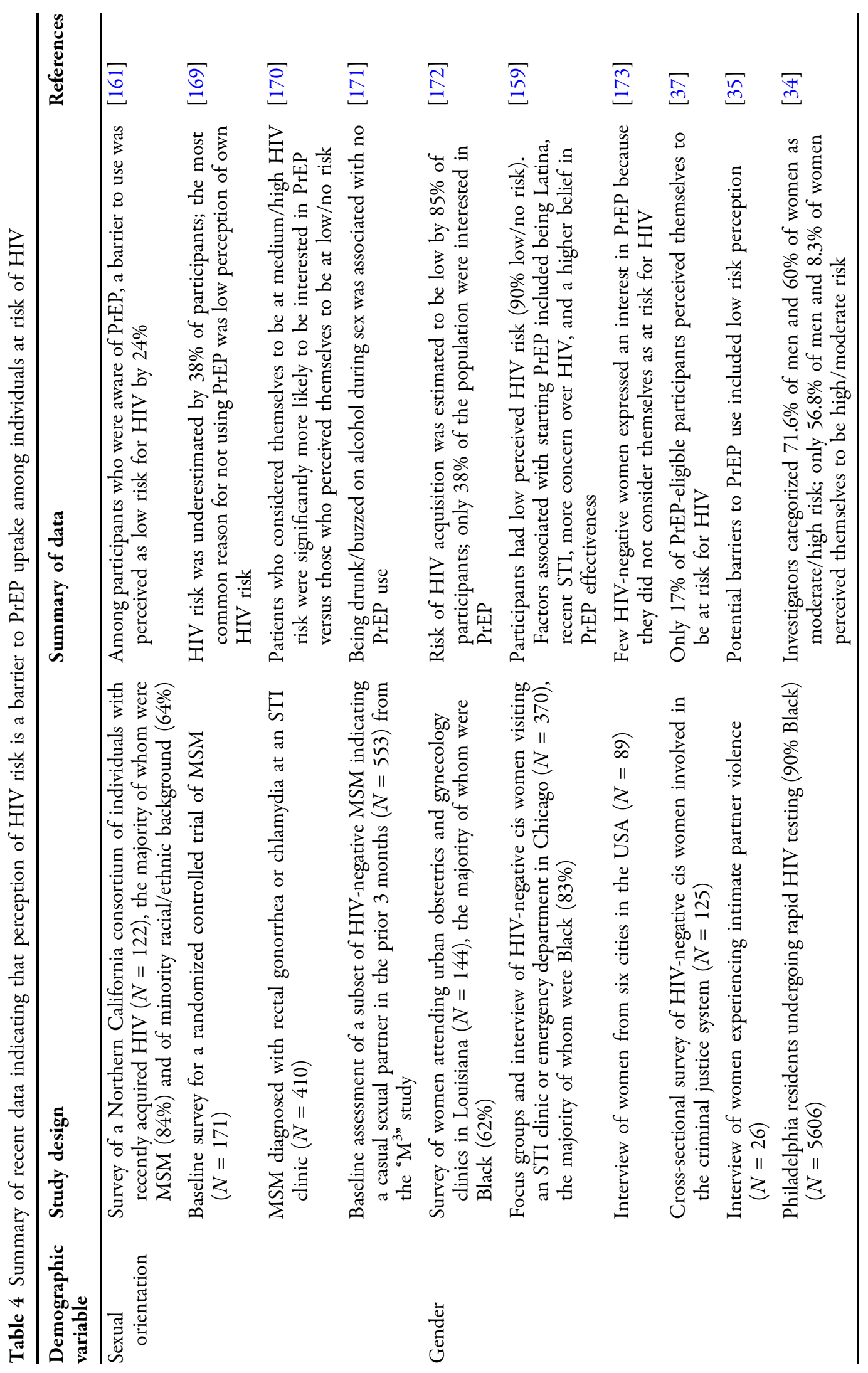




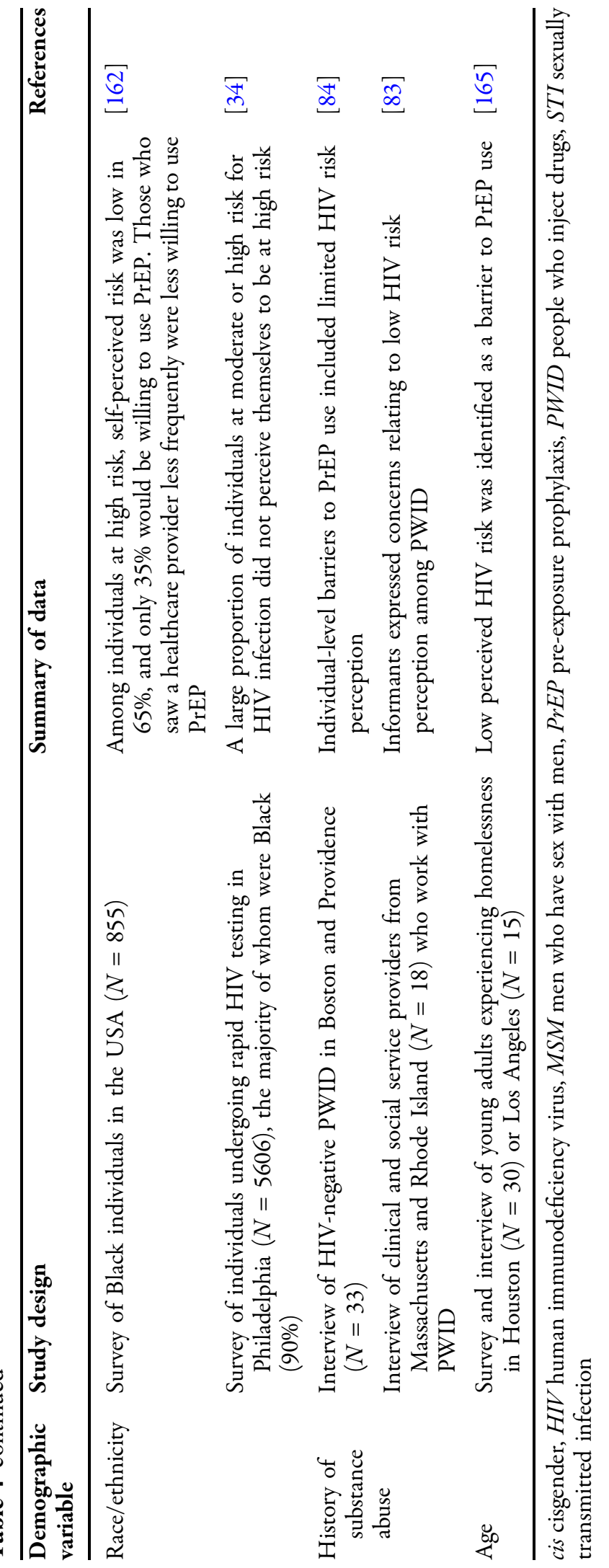


likely to come into contact with such individuals $[29,30]$. This creates a "purview paradox" in which each group of healthcare professionals believes that the other is best equipped to provide PrEP $[29,30]$. One study interviewed 30 healthcare professionals, including 17 providers who worked in a setting specializing in the care of HIV-positive individuals, on topics including who should be responsible for prescribing PrEP [29]. Both HIV specialists and primary care providers thought that primary care settings were a good site for provision of PrEP, as this is where people at high risk for HIV could be identified. However, there were concerns about a lack of specialist knowledge and bias in the primary care setting, with one HIV specialist stating about primary care: "They have minimal knowledge, and even though they may be treating some people, have probably some prejudice, or at least ambivalence." It was felt that more training would be needed for primary care settings to offer PrEP.

Specific knowledge about PrEP medication, particularly how they work and the potential side effects, have also been highlighted as critical aspects for provision of PrEP by healthcare professionals [29]. Reluctance to prescribe PrEP may stem from provider misconceptions, such as concern that poor adherence may result in development of resistance $[24,31]$ despite the fact that clinical evidence to date suggests that HIV drug resistance with PrEP use rarely occurs $[32,33]$.

\section{LOW PERCEPTION OF HIV RISK AS A BARRIER TO PREP UPTAKE}

Some individuals who would be considered, by objective risk assessment, to be at risk for HIV perceive their own risk to be low. This can create another potential barrier to PrEP uptake, albeit with some conflicting evidence. One study has shown that some HIV-negative individuals at risk of infection (including MSM and PWID) perceive themselves to be at risk, are aware of PrEP, and show greater interest in using it than those without these risk factors [19]. However, many other studies have repor- ted several demographic populations at high risk of HIV perceiving themselves to be at low risk, as summarized in Table 4 . This is illustrated by data from a study of 5606 Philadelphia residents undergoing rapid HIV testing, where the investigators categorized $71.6 \%$ of men and $60.0 \%$ of women as moderate/high risk; in contrast, only $56.8 \%$ of men and $8.3 \%$ of women perceived themselves to be high/moderate risk [34]. Populations reported to have low perceived risk include some MSM, despite their disproportionate HIV risk [8], and women at increased risk of $\mathrm{HIV}$ acquisition including Black women, women experiencing genderbased violence, and women involved in the criminal justice system [8, 35-37]. One study also highlighted "lack of concern about HIV" as a barrier to PrEP uptake in adolescent and young adult transgender men and women [38].

Another related individual-level barrier to PrEP access is low prioritization, which may be multifactorial. Prioritization may be a consequence of low HIV risk perception [39], substance use [40], or other behavioral health concerns [41]. In the USA, HIV prevalence is higher among people with serious behavioral health challenges (e.g., recurrent major depressive disorder, bipolar disorder, psychotic disorder, or comorbid mood disorder) compared with the general population [41-43]. Social factors related to poverty that limit women's access to antiretroviral therapy [44] may also impact PrEP prioritization: a 2017 review noted that "unemployment, unstable housing, and food insecurity may render accessing PrEP and taking PrEP as unimportant if women are unable to fulfill their basic needs for food and shelter" [45]. Another setting in which accessing PrEP may be deprioritized is for MSM who are released from incarceration: one study participant stated, "When you go home you have so much to do... you have to go back to welfare to get food stamps... so much different stuff... you're not really going to be thinking about 'I've got to go to the doctor's [office] right away to get my PrEP'" [46]. Competing priorities have also been identified as major barriers to healthcare in general among homeless adults, 
for whom meeting basic needs for food, shelter, and safety outweigh healthcare needs [47].

PrEP implementation may also be reduced as a result of insufficient ascertainment of HIV risk by healthcare providers. In a survey of advanced practice nurses in Indiana, their comfort with discussing/prescribing PrEP was about 80\% with gay or heterosexual couples in a monogamous relationship with one partner living with HIV infection, about $70 \%$ for PWID, and $60 \%$ for MSM who did not indicate their relationship status [48]. In a survey of health directors in North Carolina $(N=56)$, a perceived lack of suitable PrEP candidates was reported by $26 \%$ of respondents from departments not prescribing or referring individuals for PrEP [23]. Recently, a paradox concerning perception of risk and willingness to prescribe has been noted in an online survey completed by 111 medical students [49]. Results showed that willingness to prescribe was inconsistent with patient risk, with fewer students willing to prescribe PrEP if the patient was engaging in riskier behaviors such as not using condoms or having multiple partners. This was attributed to misconceptions about the effectiveness of PrEP and to personal biases related to sexuality and sexual orientation.

\section{SOCIAL STIGMA AS A BARRIER TO PREP UPTAKE}

Social stigma perceived and/or experienced by individuals at risk of HIV is a major barrier to PrEP use (Table 5). This may stem from historical stigma surrounding HIV/AIDS (both the disease itself and being a member of a group considered at risk, i.e., sexual, gender, racial and/or ethnic minority); for example, transgender women in one focus group had concerns that by taking PrEP they would be mistakenly identified as HIV-positive [50]. It may also be stigma relating specifically to PrEP. The latter is largely attributable to "PrEP shaming" - the belief that PrEP users engage in reckless sexual behavior-and was a topic of much debate following the labeling of PrEP users as "Truvada whores" in 2012 [51, 52]. The evidence summarized in Table 5 suggests that PrEP stigma persists: participants from several studies reported experience of PrEP-related stigma that manifested in a number of ways, including stereotyping, rejection, and discrimination (including homophobia, transphobia, racism, and sexism), all of which were identified as barriers to PrEP use (Table 5).

The social stigma experienced by individuals may be compounded by PrEP-related stigma at the healthcare provider level. Some providers have been concerned by an increase in sexual behavior by PrEP users due to their perception that their HIV susceptibility is decreased, known as "risk compensation," and this may foster reluctance to prescribe PrEP [53-56]. A survey of 266 primary care physicians found those who had never prescribed PrEP or referred one of their patients for PrEP were more likely to believe that PrEP use would lead to risk compensation compared with those who had adopted PrEP (prescribed/referred) [53]. In a survey of 573 providers in the USA and Canada, risk compensation was also identified as a reason for providers not prescribing PrEP. Respondents were concerned that PrEP could create a "false sense of security," and that if individuals would not use condoms then they would not use pills. Assumptions made by providers impact their perception of the likelihood of risk compensation. One study found medical students to stereotype Black MSM as more likely than White MSM to engage in increased condomless sex when on PrEP. This racial bias was associated with reduced willingness to prescribe PrEP [57].

\section{PROVIDER BIAS AND DISTRUST OF HEALTHCARE PROVIDERS/ SYSTEMS AS A BARRIER TO PREP UPTAKE}

Implicit racial and ethnic bias by healthcare professionals in the USA is well documented and can impact treatment decisions. One systematic review identified 15 studies that assessed implicit bias by healthcare professionals; 14 of these studies reported low-to-moderate levels of racial/ethnic bias among healthcare 
professionals. This implicit bias was significantly related to treatment decisions, patient-provider interactions, adherence, and, critically, patient outcomes [58]. A second systematic review found that $31 / 37$ eligible studies reported racial/ethnic bias among US healthcare professionals, and of 14 studies that related bias with outcomes, six related higher implicit bias with treatment disparities [59]. Further, according to the 2011 "Report of the National Transgender Discrimination Survey" of 6540 transgender and gender non-conforming people across all 50 states, one-fifth reported being refused care, and almost one-third had been subject to harassment in a healthcare setting [60]. Beyond the individual provider level, there are also systemic biases: a widely used algorithm in US healthcare systems was found to exhibit significant racial disparity [61]. For patients assigned the same risk level by the algorithm, in reality, Black patients had increased signs that their medical condition was not controlled, compared with White patients with the same condition. This bias arose because the algorithm made predictions based on cost, rather than illness, which reflected spending inequalities for Black and White patient communities. It is unsurprising, therefore, that there remains a significant level of distrust of healthcare systems among some patient groups.

Distrust of healthcare providers/systems was identified as a key barrier to PrEP uptake (Table 6), particularly in populations with disproportionate HIV risk. As noted previously, feelings of distrust may be attributed to social stigma at the provider level; in a number of studies, participants were alienated from their healthcare system as a result of experienced and anticipated discriminatory judgment from providers in the form of racism or homophobia (Table 6). Furthermore, there have been a number of malign events in the US medical establishment that have led to distrust in the healthcare system, particularly for Black communities (e.g., the Tuskegee syphilis study, the case of Henrietta Lacks, and the 1946-1948 Guatemalan sexually transmitted disease experiments) [62-65]. Medical distrust can also manifest as conspiracy beliefs; such beliefs have acted as a barrier to HIV prevention in the USA for years, with high prevalence within some Black communities attributed to historical racial discrimination [66-68]. A similar pattern seems to be emerging with respect to PrEP. In a survey of Black and White MSM and transgender women who have sex with men $(N=264)$, conspiracy beliefs related to PrEP were endorsed by $42 \%$ of the population and were more frequently reported by Black than White participants. These beliefs included "The CDC cannot be trusted to tell gay communities the truth about PrEP" and "When it comes to PrEP, drug companies are lying and taking advantage of us" [68]. Other studies support high prevalence of HIV conspiracy beliefs among Black MSM in the USA, one of which reported a lower intention to adopt PrEP among those with a conspiracy belief $[69,70]$.

Finally, some patients may also have doubts about the validity of clinical data for the use of PrEP in specific patient groups. Black MSM, cisgender women, and transgender women have been reluctant to participate in clinical research, and consequently are underrepresented in clinical trials [71-73]. One study found that lack of data on PrEP in specific populations was a barrier to PrEP uptake [50].

\section{LACK OF ACCESS TO MEDICAL CARE AS A BARRIER TO PREP UPTAKE}

At the individual level, there are simple logistical constraints to accessing PrEP, exacerbated by socioeconomic inequalities. For example, individuals may experience difficulty in getting to the clinic [74] due to lack of transportation [46] or time constraints [75, 76]. A 2016 National Survey on HIV in the Black community found that $38 \%$ of 787 participants were more than one hour's drive from a PrEP provider. People living in regions with higher PrEP clinic density were found to be significantly more willing to use PrEP [77]. Individuals at risk may also lack access to providers where PrEP is routinely offered [78], or may not have access to medical care of adequate quality, such as lesbian, gay, bisexual, transgender, and queer (LGBTQ)-sensitive care [79]. 
PrEP access by individuals at risk may also be impeded by barriers at the healthcare system/ provider level [80]. Many of these are logistical barriers present in the healthcare system, such as pharmacy impediments (e.g., difficulty having prescriptions filled) $[20,81]$, lack of formal prescribing protocols [82], or absence of service provision in certain geographic locations [23, 82, 83]. For example, in a county-level analysis, the Southern region of the USA was found to account for only one-quarter of PrEPproviding clinics, despite representing over half of all new HIV diagnoses. Of note, the disparity in PrEP clinic density in Southern USA also contradicts need in terms of underrepresentation in areas with lower income, higher Black and Latinx/Hispanic populations, and less insurance coverage [82]. Another barrier to PrEP access at the healthcare system level is limited delivery of PrEP to difficult-to-reach populations, such as PWID and homeless individuals, on account of inadequate infrastructure, which will need to be addressed through innovative strategies $[83,84]$.

\section{FINANCIAL BARRIERS TO PREP UPTAKE}

Financial concerns have been identified as common barriers to PrEP use across most populations at risk, including MSM, PWID, cisgender women, transgender women, young people, and homeless people (Table 7).

In addition to the studies highlighted in Table 7 , media reports of insurance companies denying coverage to HIV-negative individuals who use PrEP $[85,86]$ and employers excluding PrEP from their insurance policies [87] have highlighted further barriers to accessing PrEP.

Patient concerns over insurance and ability to pay may in turn impact healthcare provider willingness to prescribe or discuss PrEP. For example, in one study of Washington State medical providers, while concerns about PrEP cost were frequent $(43 \%)$, providers felt very $(27 \%)$ or somewhat $(45 \%)$ uncomfortable discussing cost and insurance issues [27]. In another study, low cost/insurance coverage was a facilitating factor for PrEP prescription by physicians providing primary care to adolescents (13-21 years old) [31]. Furthermore, cost may be a factor in negative provider attitudes toward PrEP, with some dismissing the preventive therapy as an "expensive condom" [55].

A cost-related barrier to uptake of PrEP may also be lack of knowledge around co-pays, or the availability of financial assistance, i.e., how to find programs and, once found, how to navigate the program requirements [88]. Thus, patient concerns around cost are both a reflection of misinformation in general communities, as well as lack of knowledge and misinformation from the providers themselves.

\section{SIDE EFFECTS/MEDICATION INTERACTION CONCERNS AS A BARRIER TO PREP UPTAKE}

Another barrier to PrEP use is the experience and/or anticipation of PrEP side effects and/or medication interactions. Many studies, in various demographic populations, have captured concerns around short- and long-term safety of PrEP among individuals at risk (Table 8). Safety concerns were also reported in a large study at a New York City health center focusing on sexual and general health for LGBTQ communities; of 1208 PrEP users, 783 reported barriers; 67 reported side effects as a barrier to PrEP use, nine of whom stopped taking PrEP [20]. In addition, transgender individuals have specific concerns regarding PrEP and interactions with hormonal treatment [50, 89-91]. Finally, although there are no data in the literature to quantify the actual impact on PrEP uptake, anecdotally there are concerns that misleading lawyer advertisements about lawsuits concerning F/TDF in the USA may play into patients' concerns around PrEP side effects, leading them to discontinue or refuse PrEP medication [92]. Similarly, discussion of side effects on social media platforms could influence perceptions about PrEP and limit uptake [93-95].

Provider concerns around PrEP side effects and safety may impact their prescribing practices, exacerbating barriers to PrEP use. This barrier is closely linked with knowledge about PrEP and understanding of the benefit/risk 
profile. A number of studies identified providerlevel stigma with respect to PrEP safety; concerns around side effects/adverse events have been linked with negative attitudes toward PrEP and reduced intention to prescribe it $[53,55,96,97]$. This is supported by a study of attitudes toward PrEP among physicians providing primary care to adolescents. Among 38 physicians who were interviewed, only $37 \%$ reported being somewhat or very familiar with PrEP, and concerns around side effects were identified as a barrier to PrEP use [31]. Similar findings were reported in a survey of internal medicine residents $(N=48)$, of whom $22 \%$ were unaware of PrEP and $62 \%$ had fair or poor awareness of side effects. PrEP was considered effective or safe by only $78 \%$ or $66 \%$ of participants, respectively [98].

\section{BARRIERS TO PREP PERSISTENCE}

Importantly, several of the key barriers to PrEP uptake discussed here have also been reported to hinder continued PrEP use (persistence). A study of 7148 individuals who initiated PrEP at a national chain pharmacy in the USA reported only $56 \%$ persistence in year $1,63 \%$ in year 2 , and $41 \%$ from initiation to year 2 , with the lowest persistence in women and individuals aged 18-24 years. Factors predicted to contribute to PrEP cessation included financial barriers, changes in perceived risk, and difficulties accessing healthcare services [99]. Overcoming barriers to PrEP uptake may therefore have a concurrent positive impact on adherence to PrEP.

\section{POTENTIAL SOLUTIONS TO BARRIERS}

Clinical trials and data demonstrating recent decreases in the frequency of new HIV diagnoses in areas of the USA where PrEP uptake has been greatest support the effectiveness of PrEP as an HIV preventive strategy $[2-4,100,101]$. In this review, key barriers to PrEP uptake were identified, including knowledge/awareness of PrEP; perception of HIV risk; social stigma; provider bias and distrust of healthcare providers/systems; lack of access to medical care; lack of access to (or awareness of) financial assistance options; and PrEP side effects and medication interaction concerns (Table 1). The barriers described have tended to be observed in populations at greatest risk with the lowest PrEP uptake, and may also originate at the provider level. Furthermore, barriers that prevent uptake are not universal, and can be population-specific, exacerbated by co-prevalent syndemic conditions such as racism, homophobia, poverty, inadequate education, and behavioral health issues. The findings presented here have also been identified by others, who have noted similar common barriers overall [102-104] and in population groups at highest risk [105-112].

Improved education or training of individuals at risk and providers will be essential in overcoming a range of barriers to PrEP uptake. To raise awareness and uptake of PrEP among individuals at risk, delivery of brief educational sessions for visitors to sexual health clinics could be an effective approach [113], as could provision of online resources such as those developed by the New York City Department of Health and Mental Hygiene [114] and The National Lesbian, Gay, Bisexual and Transgender (LGBT) Health Education Center at the Fenway Institute [115]. Social marketing campaigns also have the potential to reach millions of individuals, as demonstrated by the PrEP4Love campaign in Chicago [116]. However, despite the well-documented need to increase awareness of PrEP, a recent systematic review found that very few ongoing studies were addressing this need, particular noting a paucity of research on educational interventions targeted at cisgender women, transgender women, transgender men, PWID, and in Southern regions of the USA [117].

Education may also instill trust in healthcare providers/systems among individuals at risk. For example, improved accessibility and credibility of HIV prevention messaging in minority subpopulations has been proposed as a strategy to negate the impact of PrEP-related conspiracy beliefs [70]. Social media-based, peer-led interventions could also confer a significant population-level impact on PrEP uptake among young Black and Latinx individuals by addressing issues such as knowledge/awareness, 
Table 5 Summary of recent data indicating that social stigma is a barrier to PrEP uptake among individuals at risk of HIV

\begin{tabular}{llll}
\hline $\begin{array}{l}\text { Demographic } \\
\text { variable }\end{array}$ & Study design & Summary of data & References
\end{tabular}

\begin{tabular}{ll}
\hline $\begin{array}{c}\text { Sexual } \\
\text { orientation }\end{array}$ & $(N=43)$
\end{tabular}

PrEP stigma was experienced as rejection by potential/actual partners, being subject to stereotypes of promiscuity/chemsex, and labeling (both the user and the medication)

Interview of incarcerated MSM at the Rhode Island Department of Corrections $(N=26)$

Post-release barriers to PrEP uptake and adherence included anticipated partner or family disapproval

Interview of Black MSM PrEP users in Los Angeles $(N=26)$

Participants reported multiple experiences of PrEP-related stigma, including the perception of elevated sexual risk behaviors; conflicts in relationships; assumptions that users are HIVpositive; and gay stigma in families

Focus groups of MSM in New York City $(N=24)$

Participants thought that stigma against PrEP users was declining as PrEP became more common, but stigma remained for those not using condoms and in relation to suspicions of infidelity with PrEP use

Focus groups of young men and TGM and TGW who have sex with men in Boston, Chicago, and Los Angeles $(N=36)$

Focus groups of gay, bisexual, and other MSM in Boston, Massachusetts and Jackson, Mississippi $(N=35)$

Stigma and marginalization were highlighted as barriers to PrEP use

Participants from Jackson, in particular, expressed fear that information would be disclosed to family and friends. One person suggested that stigma related to gay sex might be a barrier to people seeking PrEP

Interview of MSM in the USA $(N=3932)$ and Sub-Saharan Africa $(N=4063)$

Interview of current and potential PrEP users in Alabama $(N=44)$, the majority of whom were gay or lesbian $(66 \%)^{\mathrm{a}}$

Gender

Focus groups of TGW living in New York City $(N=18)$

Online survey of HIV-negative, heterosexually active PrEP-inexperienced women in Connecticut who were planning parenthood $(N=597)$

Individuals in the USA were more likely to avoid healthcare support/intervention if they had not disclosed their sexual behavior to their family

Sexuality-related stigma was raised as a perceived barrier to PrEP access

Stigma and exclusion of TGW from advertising were identified as barriers to PrEP use

PrEP-user stereotypes were commonly experienced, with many believing others would regard them as promiscuous (37\%), HIV-positive (32\%), bad (14\%), or gay (11\%). Thirty percent reported they would feel ashamed to disclose PrEP use; many expected disapproval from family (36\%), sexual partners (34\%), and friends (25\%)

Group discussions among cis and TGW of color at the "Empowering Women's Health Summit" in $2018(N=279)$

Race/ethnicity Survey of HIV-negative cis women who completed enrollment for a PrEP clinical trial in Southern California $(N=136)$

Participants identified cultural gender norms and roles as an overarching barrier to PrEP use; other barriers included lack of effective communication with healthcare providers, structural racism, and stigmatization

Black women were less likely to know if their partner was HIV-positive, compared with White and Latina women 
Table 5 continued

\begin{tabular}{ll}
\hline $\begin{array}{l}\text { Demographic } \\
\text { variable }\end{array}$ & Study design \\
\hline $\begin{array}{l}\text { History of } \\
\text { substance } \\
\text { abuse }\end{array}$ & $\begin{array}{c}\text { Interview of HIV-negative PWID in Boston } \\
\text { and Providence }(N=33)\end{array}$ \\
& $\begin{array}{r}\text { Survey of PWID recruited to a mobile syringe } \\
\text { exchange program in New Jersey }(N=138)\end{array}$
\end{tabular}

Age

Survey of young (age 18-30 years) HIV-positive minorities in South Texas $(N=92)$

Survey and interview of young adults experiencing homelessness in Houston $(N=30)$ or Los Angeles $(N=15)$

Summary of data

References

HIV-related stigma within social networks was identified as a barrier to PrEP use

[84]

Participants reported substantial barriers to PrEP, including feeling embarrassed $(45 \%)$ or anxious (52\%) about taking PrEP, and nondisclosure to partners $(51 \%)$

Interview of physicians providing care to 13-21- Participants reported lack of acceptability to year-old adolescents $(N=38)$

A total of $43 \%$ of participants reported that they would be embarrassed to ask for PrEP

Identified barriers to PrEP use included perceived stigma of PrEP use

Survey of young MSM in California using geosocial networking apps $(N=687)$ parents as a barrier to PrEP use

Stigma was identified as a factor in low willingness to take PrEP, e.g., concern around family members or friends finding out about PrEP use

Survey of PrEP-indicated emerging MSM aged $18-25$ years $(N=194)$

Only approx. $20 \%$ of participants reported moderate or high comfort with parent sex communication. Odds of current PrEP use increased with age, parent sex communication, and increased family disclosure of sexual identity. Participants who reported being in a relationship were less likely to be using PrEP than single participants

Survey of MSM aged $18-25$ years $(N=236)$

Participants were less likely to use PrEP if they were in a relationship

Online surveys and focus groups of adolescents $(N=56)$, most of whom were cis male (95\%) and identified as gay (79\%)

A frequently reported barrier was homophobia in the form of disapproving parents and healthcare providers

Online focus groups of HIV-negative sexual and Participants asked a variety of questions about gender minority adolescents (aged 14-18 years) recruited from across the USA PrEP, including how or where to get PrEP without parents finding out

Geographic

Focus groups of individuals at high risk of HIV location $^{\mathrm{a}}$ in the Deep South $(N=54)$, primarily Black MSM and women participating in substance use treatment

Participants described substantial levels of stigma, including HIV-related stigma and discrimination from family, church, and community

cis cisgender, $H I V$ human immunodeficiency virus, $M S M$ men who have sex with men, $\operatorname{PrEP}$ pre-exposure prophylaxis, $P W I D$ people who inject drugs, $T G M$ transgender men, $T G W$ transgender women

a Please see study of current and potential PrEP users in Alabama "Sexual orientation" category, also applicable here [76] 
attitudes, stigma, and treatment access [118]; similar interventions could successfully reach transgender women and MSM. Counseling on the benefits of PrEP, and providing information and reassurance on the risk and monitoring of short- and long-term side effects, may also improve adherence to PrEP [119].

It is also imperative that educational interventions are targeted to primary care providers, including training to increase PrEP knowledge [120] and to alleviate concerns regarding PrEP safety [98]. Concerns around risk compensation (or an increase in risk-taking behaviors among individuals at risk prompted by a decrease in perceived HIV risk) appear to be one factor that can cause reluctance among some healthcare providers to prescribe PrEP to eligible patients [53]. While several studies have reported risk compensation behavior in individuals receiving PrEP [121-123], the balance of evidence suggests that patients who are eligible for PrEP inherently have a high baseline risk for STIs, which remains high following initiation of treatment with PrEP [88, 124-128]. Even if risk compensation does occur in some individuals or populations, related concerns do not justify withholding PrEP from people at risk for HIV infection [56]. Consistent with this notion, it has been proposed that PrEP be viewed as an opportunity for improved STI control [124, 129], whereby an increase in detection rates due to more frequent STI testing, with potentially earlier diagnosis and treatment, may counteract or surpass any negative effects of risk compensation [130]. Nevertheless, patients receiving PrEP should be provided with support for risk-reduction behaviors [33]. Similarly, misconceptions around the development of treatment resistance may also account for the reluctance of some providers to prescribe PrEP $[24,31]$. However, there is little evidence supporting the development of treatment resistance with the use of PrEP medications. The number of reported cases is extremely low, with the majority occurring in individuals with undiagnosed HIV infection or during sporadic unsupervised use [32, 33, 131], thus highlighting the importance of testing for HIV prior to PrEP initiation and regularly during use of PrEP, per clinical guidelines [33].
Education targeted to primary care providers has been shown to be effective: after an educational intervention, the proportion of participants (internal medicine residents) who believed PrEP was safe increased from $66 \%$ to $92 \%$ and the proportion who believed it was effective increased from $78 \%$ to $94 \%$. Before training, only one-third of participants were likely to prescribe PrEP in the next 6 months, which increased to two-thirds after training [98]. Healthcare professionals wishing to prescribe PrEP and who want to learn more about its implementation can refer to current CDC/US Public Health Service (USPHS) clinical guidelines for comprehensive information on the use of daily oral antiretroviral PrEP to reduce the risk of acquiring HIV infection in adults [33]. Complementary information can also be found in the World Health Organization implementation tool for PrEP of HIV infection [132] and the US Preventive Services Task Force Recommendation Statement on PrEP [133, 134]. A summary of guidance for implementing PrEP in clinical practice is provided in Table 9.

Training may also be employed to improve cultural humility [104] and to overcome the potential impact of implicit bias, stereotypes, and anticipated risk compensation on willingness to prescribe [135]. However, to truly address bias entrenched in the healthcare system, changes need to be made at a societal level. The ultimate aim should be that the healthcare community workforce adequately reflects the populations it treats; programs that increase the number of Black, Latinx, and LGBTQ healthcare professionals are needed.

Some individual-level barriers to access, such as not knowing where to get PrEP [74, 136], should be relatively straightforward to address through improved communication with individuals at risk. However, improving access to PrEP will require innovative approaches to delivery of care. It is important that these strategies extend PrEP outreach by engaging a diverse range of providers, including those from non-traditional settings such as pharmacies, mental health clinics, substance use clinics, emergency rooms (ERs), HIV testing centers, correctional institutions, and community-based organizations [137]. For example, integration of 
HIV screening into ERs has been highly successful [138]. This and the apparent willingness of individuals who are at risk to accept PrEP from ER providers suggest that ERs could provide a setting to facilitate quick connections with PrEP providers [137]. For non-emergency settings, pharmacies should play an important role in PrEP implementation in the community [104]. The One-Step PrEP ${ }^{\circledR}$ program, a pharmacist-managed approach that allows PrEP access following a single patient encounter, has been shown to be logistically and financially feasible, with positive responses from individuals seeking PrEP [139, 140]. Between March 2015 and February 2018, 695 patients initiated PrEP via the One-Step $\operatorname{PrEP}^{\circledR}$ program and 98\% had a zero-dollar patient responsibility per month. The dropout rate was $25 \%$, and although 207 sexually transmissible infection diagnoses were made, no HIV seroconversions were reported [141]. State legislation, such as California Senate Bill 159, which allows pharmacists to provide PrEP medications without a prescription, may further expand pharmacist-led PrEP efforts and access in the USA. Integration of mental health screening into HIV healthcare has also been proposed as a strategy to improve HIV prevention [41]. Regardless of treatment setting, the development of stronger guidelines and policies for PrEP providers [97], along with the establishment of partnerships and effective communication between medical and social service providers [102], is needed. The World Health Organization reported that one of the critical enablers for programs to prevent and treat HIV was addressing basic needs, such as shelter, food, hygiene, childcare, recreation, and employment [142]. PrEP prevention programs targeted to certain populations may need to collaborate with programs and agencies who can provide this support.

Leveraging technology can make PrEP accessible to more patients; PrEP uptake may be supported by app-based delivery models such as TelePrEP, which connects individuals to a PrEP provider using a phone or computer [14, 143]. Similar approaches designed to reduce the patient and provider burden may also encourage PrEP persistence. As an illustration, the "PrEP@Home" model, designed to decrease monitoring by replacing quarterly PrEP followup visits with home care, was found to be acceptable by participants in a pilot study, and was in demand for future use [144]. This approach could be especially valuable to those without access to transportation [144] or those affected by the stigma of HIV. A pharmacybased TelePrEP model was implemented in a large county hospital in Atlanta in February 2018: 41 out of 44 patients who started PrEP (93\%) remained on PrEP in 2019 [145].

Among the easily surmountable barriers to PrEP uptake may be treatment cost and insurance coverage. While there is evidence to support cost as a perceived barrier to PrEP uptake for those who present for PrEP, the actual scale of this problem may be limited. A recent independent study of nationally representative data, including authors from the CDC, demonstrated that fewer than $1 \%$ of the individuals with indications for PrEP required financial assistance for both PrEP medication and clinical care [146]. An additional 7\% required financial assistance only for PrEP clinical care (not PrEP medication). Thus, only a small number of patients were not financially covered for clinician visits or laboratory tests, and an even smaller number had no coverage for medication and clinical costs of PrEP care [146]. Regardless, there is a proportion of patients, albeit small, with an unmet need for financial assistance in PrEP care. Efforts of the US Department of Health and Human Services' "Ready, Set, PrEP" program may help to address the unmet need in this population through provision of PrEP medication at no cost to qualifying recipients. This initiative is a component of the US government's wider plan to "End the Epidemic," which aims to reduce new HIV infections in the USA by $75 \%$ in 5 years and by $90 \%$ by 2030 [147, 148].

Starting in 2021, on the basis of the Affordable Care Act, private insurers will be obliged to cover PrEP as a result of the intervention receiving Grade $A$ recommendation from the US Preventive Services Task Force [133, 134]. In addition, 2019 saw the introduction of the PrEP Access and Coverage Act to the Senate, which would require all private and public insurance plans to cover the costs of accessing PrEP [149]. 
Table 6 Summary of recent data indicating that distrust of healthcare providers/systems is a barrier to PrEP uptake among individuals at risk of HIV

\begin{tabular}{|c|c|c|c|}
\hline $\begin{array}{l}\text { Demographic } \\
\text { variable }\end{array}$ & Study design & Summary of data & References \\
\hline \multirow[t]{7}{*}{$\begin{array}{l}\text { Sexual } \\
\text { orientation }\end{array}$} & $\begin{array}{l}\text { Survey of MSM at two Atlanta-based Gay } \\
\text { Pride events in } 2018(N=381)\end{array}$ & $\begin{array}{l}\text { More than half of participants were willing } \\
\text { to be screened for PrEP in pharmacy (with } \\
\text { Black MSM being significantly less willing } \\
\text { than White MSM) and one-third were } \\
\text { unwilling to discuss PrEP with pharmacy } \\
\text { staff }\end{array}$ & [186] \\
\hline & $\begin{array}{l}\text { Focus groups of MSM in New York City } \\
(N=24)\end{array}$ & $\begin{array}{l}\text { Many participants reported mistrust of } \\
\text { medical providers }\end{array}$ & {$[175]$} \\
\hline & $\begin{array}{l}\text { Interview of gay, bisexual, and other MSM } \\
\text { involved in the criminal justice system } \\
(N=26)\end{array}$ & $\begin{array}{l}\text { Participants noted the following reasons for } \\
\text { mistrust: feelings of dehumanization; lack } \\
\text { of privacy leading to belief that medical } \\
\text { care is not confidential; and belief that } \\
\text { status as an incarcerated person influences } \\
\text { care received }\end{array}$ & {$[187]$} \\
\hline & $\begin{array}{l}\text { Survey of Black MSM in Southeastern USA } \\
\qquad(N=147)\end{array}$ & $\begin{array}{l}\text { Perceived healthcare-related discrimination } \\
\text { was negatively associated with PrEP } \\
\text { awareness }\end{array}$ & {$[188]$} \\
\hline & $\begin{array}{l}\text { Focus groups of Black MSM aged } \\
16-25 \text { years in Milwaukee }(N=44)\end{array}$ & $\begin{array}{l}\text { Previous/anticipated negative interactions } \\
\text { (perceived racism/homophobia) with } \\
\text { physicians and skepticism about the } \\
\text { healthcare system were reported to have } \\
\text { alienated young Black MSM from the } \\
\text { healthcare system and created barriers to } \\
\text { PrEP use }\end{array}$ & [189] \\
\hline & $\begin{array}{l}\text { Interview of Black MSM PrEP users } \\
\qquad(N=26)\end{array}$ & $\begin{array}{l}\text { Participants reported judgement from } \\
\text { medical providers, and discomfort with } \\
\text { medical providers }\end{array}$ & {$[174]$} \\
\hline & $\begin{array}{l}\text { Focus groups of gay, bisexual, and other } \\
\text { MSM in Boston, Massachusetts and } \\
\text { Jackson, Mississippi }(N=35)\end{array}$ & $\begin{array}{l}\text { Participants from Jackson had a palpable and } \\
\text { emphatic degree of medical mistrust, and } \\
\text { described a strong aversion to medical care } \\
\text { in Black communities; they also expressed } \\
\text { skepticism about the effectiveness of PrEP }\end{array}$ & {$[167]$} \\
\hline
\end{tabular}


Table 6 continued

\begin{tabular}{|c|c|c|c|}
\hline $\begin{array}{l}\text { Demographic } \\
\text { variable }\end{array}$ & Study design & Summary of data & References \\
\hline \multirow[t]{4}{*}{ Gender } & $\begin{array}{l}\text { Data from HIV-negative TGW aged } \\
\text { 16-29 years enrolled in Project LifeSkills } \\
\text { during 2012-2015 }(N=230) \text {, the } \\
\text { majority of whom were of color }(67 \%)\end{array}$ & $\begin{array}{l}\text { Having a medical provider who meets health } \\
\text { needs was associated with higher PrEP } \\
\text { acceptability scores }\end{array}$ & {$[164]$} \\
\hline & $\begin{array}{l}\text { Group discussions among cis and TGW of } \\
\text { color at the "Empowering Women's } \\
\text { Health Summit" in } 2018(N=279)\end{array}$ & $\begin{array}{l}\text { Distrust of medical providers was identified } \\
\text { as a barrier to PrEP use }\end{array}$ & [179] \\
\hline & $\begin{array}{l}2017 \text { cross-sectional survey of HIV-negative, } \\
\text { PrEP-inexperienced and heterosexually } \\
\text { active adult women }(N=501)\end{array}$ & $\begin{array}{l}\text { Black women expressed higher levels of } \\
\text { medical mistrust than White women, } \\
\text { which was also associated with lower } \\
\text { comfort discussing PrEP }\end{array}$ & {$[190]$} \\
\hline & $\begin{array}{l}\text { Focus groups and interviews with TGW in } \\
\text { San Francisco }(N=30)\end{array}$ & $\begin{array}{l}\text { Transgender-specific barriers included } \\
\text { medical mistrust due to transphobia }\end{array}$ & [89] \\
\hline Race/ethnicity & $\mathrm{a}, \mathrm{b}, \mathrm{c}$ & & \\
\hline $\begin{array}{l}\text { History of } \\
\text { substance } \\
\text { abuse }\end{array}$ & $\begin{array}{l}\text { Interview of HIV-negative PWID in Boston } \\
\text { and Providence }(N=33)\end{array}$ & $\begin{array}{l}\text { Negative experiences with healthcare } \\
\text { providers was identified as a barrier to } \\
\text { PrEP use }\end{array}$ & {$[84]$} \\
\hline \multirow[t]{3}{*}{$\mathrm{Age}^{\mathrm{b}}$} & $\begin{array}{l}\text { Cross-sectional data from an ongoing cohort } \\
\text { study of young sexual-minority men in } \\
\text { New York City }(N=492)\end{array}$ & $\begin{array}{l}\text { Participants with greater concerns around } \\
\text { talking with their provider about their } \\
\text { sexual behaviors were less likely to use } \\
\text { PrEP }\end{array}$ & [191] \\
\hline & $\begin{array}{l}\text { Online surveys and focus groups of } \\
\text { adolescents }(N=56) \text {, most of whom were } \\
\text { cis male }(95 \%) \text { and identified as gay }(79 \%)\end{array}$ & $\begin{array}{l}\text { A frequent barrier to PrEP use was } \\
\text { homophobia in the form of disapproving } \\
\text { healthcare providers }\end{array}$ & {$[74]$} \\
\hline & $\begin{array}{l}\text { Survey of young MSM in California using } \\
\text { geosocial networking apps }(N=687)\end{array}$ & $\begin{array}{l}\text { Greater medical mistrust was associated with } \\
\text { lower willingness to take PrEP }\end{array}$ & [181] \\
\hline
\end{tabular}

cis cisgender, $H I V$ human immunodeficiency virus, $M S M$ men who have sex with men, $\operatorname{PrEP}$ pre-exposure prophylaxis, $P W I D$ people who inject drugs, $T G W$ transgender women

a Please see study of Black MSM in the "Sexual orientation" category, also applicable here [188]

b Please see study of Black MSM aged 16-25 years in the "Sexual orientation" category, also applicable here [189]

c Please see study of Black MSM in the "Sexual orientation" category, also applicable here [174]

Despite this, addressing the financial barriers to PrEP will require affordable and high-quality insurance policies that are ubiquitously accessible to individuals at risk throughout the USA [104]. For example, dedicated PrEP service reimbursement programs have been introduced in several regions to financially assist individuals at high risk of HIV acquisition, including those who are uninsured or underinsured [150-152]. A number of states now offer PrEP DAPs (Drug Assistance Programs), which pay for medical and laboratory costs incurred by PrEP DAP enrollees [153]. However, there is not yet much overlap between the states offering 
Table 7 Summary of recent data indicating that financial concerns are a barrier to PrEP uptake among individuals at risk of HIV

\begin{tabular}{|c|c|c|c|}
\hline $\begin{array}{l}\text { Demographic } \\
\text { variable }\end{array}$ & Study design & Summary of data & References \\
\hline \multirow[t]{5}{*}{$\begin{array}{l}\text { Sexual } \\
\text { orientation }\end{array}$} & $\begin{array}{l}\text { Qualitative phone interviews with } \\
\text { attendees at a sexual health clinic in } \\
\text { New York City }(N=1208)\end{array}$ & $\begin{array}{l}58 \text { of } 1208 \text { patients who initiated PrEP reported } \\
\text { barriers stemming from insurance issues }\end{array}$ & {$[20]$} \\
\hline & $\begin{array}{l}\text { Patients with recently diagnosed HIV } \\
\qquad(N=268 \text {, mainly MSM })\end{array}$ & $\begin{array}{l}\text { Cost/insurance concerns were reported as } \\
\text { barriers in 36\% of patients }\end{array}$ & {$[161]$} \\
\hline & $\begin{array}{l}\text { Interviews with MSM at Rhode Island } \\
\text { Department of Corrections }(N=26)\end{array}$ & $\begin{array}{l}\text { Most participants were interested in taking } \\
\text { PrEP, but were concerned that access to } \\
\text { health insurance may be necessary to help } \\
\text { with the cost }\end{array}$ & {$[46]$} \\
\hline & $\begin{array}{l}\text { A large survey of young MSM } \\
\qquad(N=2297)\end{array}$ & $\begin{array}{l}\text { PrEP use was associated with having health } \\
\text { insurance }\end{array}$ & {$[10]$} \\
\hline & $\begin{array}{l}\text { Mixed-methods study of } 14-18 \text {-year old } \\
\text { MSM }(N=56)\end{array}$ & Paying for PrEP was frequently cited as a barrier & {$[74]$} \\
\hline Gender & $\begin{array}{l}\text { Interviews with women attendees at an } \\
\text { urban sexual health clinic }(N=14)\end{array}$ & Lack of insurance coverage was a concern & [81] \\
\hline Race/ethnicity & $\begin{array}{l}\text { Group discussions with cis and } \\
\text { transgender women of color in South } \\
\text { Florida }(N=279)\end{array}$ & $\begin{array}{l}\text { Insurance coverage and lack of economic } \\
\text { independence were cited as barriers }\end{array}$ & {$[179]$} \\
\hline Age & a & & \\
\hline $\begin{array}{l}\text { History of } \\
\text { substance } \\
\text { abuse }\end{array}$ & $\begin{array}{l}\text { A survey of PWID in New Jersey } \\
\qquad(N=138)\end{array}$ & $\begin{array}{l}\text { 33\% reported lack of insurance as a barrier to } \\
\text { PrEP use }\end{array}$ & {$[78]$} \\
\hline $\begin{array}{l}\text { Geographic } \\
\text { location }\end{array}$ & $\begin{array}{l}\text { Strengths-based case management } \\
\text { intervention in Florida }(N=30, \\
\text { mostly male, Hispanic, and Black) }\end{array}$ & $\begin{array}{l}\text { Financial barriers to PrEP were encountered by } \\
67 \%(20 / 30) \text { of adults }\end{array}$ & {$[80]$} \\
\hline \multirow[t]{2}{*}{$\begin{array}{l}\text { Marginalized } \\
\text { populations }\end{array}$} & $\begin{array}{l}\text { Behavioral intervention trial in female sex } \\
\text { workers in the Mexico-US border } \\
\text { region }(N=295)\end{array}$ & $\begin{array}{l}18.7 \% \text { of individuals cited perceived financial } \\
\text { barriers to } \operatorname{PrEP}\end{array}$ & {$[192]$} \\
\hline & $\begin{array}{l}\text { Mixed methods study of young adults } \\
\text { experiencing homelessness in Houston } \\
\text { and Los Angeles }(N=45)\end{array}$ & Cost was identified as a barrier to $\operatorname{PrEP}$ use & {$[165]$} \\
\hline
\end{tabular}

cis cisgender, $H I V$ human immunodeficiency virus, $M S M$ men who have sex with men, $\operatorname{PrEP}$ pre-exposure prophylaxis, $P W I D$ people who inject drugs

a Please see study of 14-18-year-old MSM “Sexual orientation" category, also applicable here [74] 
Table 8 Summary of recent data indicating that side effects/medication interaction concerns are a barrier to PrEP uptake among individuals at risk of HIV

\begin{tabular}{|c|c|c|c|}
\hline $\begin{array}{l}\text { Demographic } \\
\text { variable }\end{array}$ & Study design & Summary of data & References \\
\hline \multirow[t]{2}{*}{$\begin{array}{l}\text { Sexual } \\
\text { orientation }\end{array}$} & $\begin{array}{l}\text { Focus groups of MSM in New York City } \\
\qquad(N=24)\end{array}$ & $\begin{array}{l}\text { Concerns were raised about side effects of } \\
\text { PrEP, and this was particularly the case } \\
\text { among Black participants }\end{array}$ & {$[175]$} \\
\hline & $\begin{array}{l}\text { Focus groups of gay, bisexual, and other } \\
\text { MSM in Boston, Massachusetts and } \\
\text { Jackson, Mississippi }(N=35)\end{array}$ & $\begin{array}{l}\text { Participants concerns about side effects and } \\
\text { safety }\end{array}$ & {$[167]$} \\
\hline \multirow[t]{6}{*}{ Gender } & $\begin{array}{l}\text { Survey of Black and Latina TGW in } \\
\text { Baltimore and Washington }(N=201)\end{array}$ & $\begin{array}{l}\text { The most commonly reported barrier to } \operatorname{PrEP} \\
\text { uptake was worries about drug interactions } \\
\text { with hormone therapy }\end{array}$ & {$[91]$} \\
\hline & $\begin{array}{l}\text { Focus group of TGW in New York City } \\
\quad(N=18)\end{array}$ & $\begin{array}{l}\text { Participants raised the barriers of } \\
\text { uncomfortable side effects, difficulty taking } \\
\text { pills, and lack of research in TGW }\end{array}$ & {$[50]$} \\
\hline & $\begin{array}{l}\text { Focus groups and interview of HIV-negative } \\
\text { cis women visiting an STI clinic or } \\
\text { emergency department in Chicago } \\
(N=370) \text {, the majority of whom were } \\
\text { Black }(83 \%)\end{array}$ & $\begin{array}{l}\text { Most participants }(81 \%) \text { had concerns about } \\
\text { taking PrEP, the most common being side } \\
\text { effects }(68 \%) \text { and incomplete protection } \\
(25 \%)\end{array}$ & [159] \\
\hline & $\begin{array}{l}\text { Interview of women experiencing intimate } \\
\text { partner violence }(N=26)\end{array}$ & $\begin{array}{l}\text { Participants raised fear of side effects and } \\
\text { long-term health concerns as potential } \\
\text { barriers to PrEP }\end{array}$ & {$[35]$} \\
\hline & $\begin{array}{l}\text { Interview of women at an urban sexual } \\
\text { health clinic }(N=14)\end{array}$ & $\begin{array}{l}\text { Participants raised concerns about PrEP safety } \\
\text { as a key barrier }\end{array}$ & {$[81]$} \\
\hline & $\begin{array}{l}\text { Interviews with TGW }(N=60) \text { and TGM } \\
\qquad(N=90)\end{array}$ & $\begin{array}{l}\text { About half were extremely or somewhat } \\
\text { worried about the possibility of negative } \\
\text { medical side effects of PrEP and } 23 \% \text { did } \\
\text { not want to add another medication to } \\
\text { their health regimen }\end{array}$ & {$[38]$} \\
\hline $\begin{array}{l}\text { History of } \\
\text { substance } \\
\text { abuse }\end{array}$ & $\begin{array}{l}\text { Interview of HIV-negative PWID in } \\
\text { Boston and Providence }(N=33)\end{array}$ & $\begin{array}{l}\text { Participants raised concerns about PrEP side } \\
\text { effects }\end{array}$ & {$[84]$} \\
\hline Age & $\begin{array}{l}\text { Survey of young MSM in California using } \\
\text { geosocial networking apps }(N=687)\end{array}$ & $\begin{array}{l}\text { Concern about side effects was associated with } \\
\text { reduced willingness to take PrEP }\end{array}$ & [181] \\
\hline
\end{tabular}

cis cisgender, $H I V$ human immunodeficiency virus, $M S M$ men who have sex with men, $\operatorname{PrEP}$ pre-exposure prophylaxis, $P W I D$ people who inject drugs, $S T I$ sexually transmitted infection, $T G M$ transgender men, $T G W$ transgender women 
Table 9 Summary of PrEP implementation considerations based on the US Preventive Services Task Force Recommendation Statement $[133,134]$

Identify individuals at risk

Routinely assess sexual and injection drug use history for all patients in an open and nonjudgmental manner

Identify behaviors that make a person an appropriate candidate for PrEP

Complete baseline assessments in PrEP candidates

HIV testing and medical history to exclude persons with acute or chronic HIV infection

Kidney function testing

Serologic testing for hepatitis B

Serologic testing for hepatitis $\mathrm{C}$

Testing for other STIs

Pregnancy testing (if applicable)

Consider vaccination for hepatitis A and hepatitis B in unvaccinated individuals

Patient counseling

Counseling points should include

The importance of adherence and its correlation to effectiveness

That PrEP does not reduce the risk of other STIs

Use condoms consistently to prevent other STIs

The importance of regular screening of STIs and the need to test once patient notices signs and symptoms of STIs

On-going follow-up and monitoring

HIV testing every 3 months

Regular screening for STIs

Continue to assess HIV risk

Other considerations

Identifying persons at risk of HIV can be challenging because of stigma and discrimination against gay, bisexual, transgender, and nonbinary persons, or the lack of a trusting relationship between patient and clinician

Recognize that adherence support is a key component of providing PrEP and includes establishing trust and open communication with patients, patient education, reminder systems for taking medication, and attention to medication adverse effects

Recognize the barriers to PrEP implementation and uptake; these barriers and disparities need to be addressed to achieve the full benefit of PrEP

Patients may discontinue PrEP for several reasons, including personal preference, decreased risk of HIV acquisition, or adverse medication effects

Consult the CDC guidelines for a complete discussion of implementations considerations for PrEP [33]

CDC Centers for Disease Control, $H I V$ human immunodeficiency virus, PrEP pre-exposure prophylaxis, STI sexually transmitted infection 
PrEP DAPs and states with the highest need (states without Medicaid expansion). Efforts are required to ensure patients are better informed about the financial assistance options available to them. To this end, patients require services to help them navigate sources of support, identify financial help [80, 154], improve access to treatment, and encourage positive engagement [80].

\section{CONCLUSIONS}

In summary, successful integration of PrEP into HIV screening and prevention services has the potential to reduce HIV incidence in the USA, and help achieve the US government's goal of ending the HIV epidemic in the USA by 2030 $[147,148]$. However, optimal impact of PrEP as a preventive intervention is yet to be realized. This review has identified a complex and diverse range of barriers to PrEP uptake that exist at the social, structural, individual, and medical system/provider levels (Table 1). These include a lack of awareness of PrEP among eligible individuals and healthcare providers, fear of stigma and/or side effects, provider implicit bias, distrust of the healthcare system, and a lack of access to medical care or financial assistance. Among healthcare providers, misconceptions around the development of treatment resistance and/or the potential for risk compensation in PrEP users appear to be important factors behind the reluctance to prescribe PrEP. Overcoming these barriers will require multifaceted approaches that combine financial, social, structural, and educational interventions-not only addressing the practicalities of accessing PrEP but also acknowledging and addressing deep-rooted issues such as sociohistorical racism and systemic bias, combined with destigmatization of PrEP and its users (Table 1). Healthcare professionals wishing to prescribe PrEP can refer to current CDC/USPHS guidelines, the WHO clinical implementation tool, and the US Preventive Services Task Force Recommendation Statement (Table 9) [33, 132-134]. Furthermore, given that help for patients with navigating financial aid was identified as a barrier to uptake, both clinicians and patients should be made aware of the "Ready, Set, PrEP" program, which offers access to PrEP medication at no cost for qualifying recipients in the USA. Finally, learnings from PrEP uptake may provide important insights for the implementation of any HIV prevention strategies that are yet to come.

\section{ACKNOWLEDGEMENTS}

Funding. Funding for medical writing support for this article, and for the Rapid Service Fee and the Open Access fee, was provided by Gilead Sciences.

Authorship. All named authors meet the International Committee of Medical Journal Editors (ICMJE) criteria for authorship of this article, take responsibility for the integrity of the work as a whole, and have given their approval for this version to be published.

Medical Writing, Editorial, and Other Assistance. Medical writing support (including development of a draft outline and subsequent drafts in consultation with the authors, collating author comments, copyediting, fact checking and referencing) was provided by Emma Prest and Emma McConnell of Aspire Scientific (Bollington, UK).

Disclosures. Kenneth H. Mayer has received unrestricted research grants from Gilead and Janssen and participated in scientific advisory boards for Gilead and Merck. Allison Agwu has participated in a scientific advisory panel for Gilead and an expert advisory panel for Merck. David Malebranche has participated in Speaker's Bureaus for Gilead.

Compliance with Ethics Guidelines. This article is based on previously conducted studies and does not contain any studies with human participants or animals performed by any of the authors. 
Data Availability. Data sharing is not applicable to this article as no datasets were generated or analyzed during the current study.

Open Access. This article is licensed under a Creative Commons Attribution-NonCommercial 4.0 International License, which permits any non-commercial use, sharing, adaptation, distribution and reproduction in any medium or format, as long as you give appropriate credit to the original author(s) and the source, provide a link to the Creative Commons licence, and indicate if changes were made. The images or other third party material in this article are included in the article's Creative Commons licence, unless indicated otherwise in a credit line to the material. If material is not included in the article's Creative Commons licence and your intended use is not permitted by statutory regulation or exceeds the permitted use, you will need to obtain permission directly from the copyright holder. To view a copy of this licence, visit http:// creativecommons.org/licenses/by-nc/4.0/.

\section{REFERENCES}

1. Centers for Disease Control and Prevention. Application number: 021752Orig1s030 summary review; 2012. https://www.accessdata.fda.gov/drugsatfda docs/nda/2012/021752Orig1s030SumR.pdf. Accessed 1 July 2019.

2. Grant RM, Lama JR, Anderson PL, et al. Preexposure chemoprophylaxis for HIV prevention in men who have sex with men. N Engl J Med. 2010;363: 2587-99.

3. Baeten JM, Donnell D, Ndase P, et al. Antiretroviral prophylaxis for HIV prevention in heterosexual men and women. N Engl J Med. 2012;367:399-410.

4. Sullivan PS, Smith DK, Mera-Giler R, et al. The impact of pre-exposure prophylaxis with TDF/FTC on HIV diagnoses, 2012-2016, United States. 22nd International AIDs conference 2018, Amsterdam.

5. Sullivan PS, Giler RM, Mouhanna F, et al. Trends in the use of oral emtricitabine/tenofovir disoproxil fumarate for pre-exposure prophylaxis against HIV infection, United States, 2012-2017. Ann Epidemiol. 2018;28:833-40.
6. Smith DK, Van Handel M, Grey J. Estimates of adults with indications for HIV pre-exposure prophylaxis by jurisdiction, transmission risk group, and race/ethnicity, United States, 2015. Ann Epidemiol. 2018;28:850-7.

7. Huang YA, Zhu W, Smith DK, Harris N, Hoover KW. HIV preexposure prophylaxis, by race and ethnicity-United States, 2014-2016. MMWR Morb Mortal Wkly Rep. 2018;67:1147-50.

8. Centers for Disease Control and Prevention. HIV surveillance report; 2017. https://www.cdc.gov/hiv/ statistics/overview/index.html. Accessed 1 July 2019.

9. Edelman EJ, Moore BA, Calabrese SK, et al. Primary care physicians' willingness to prescribe HIV preexposure prophylaxis for people who inject drugs. AIDS Behav. 2017;21:1025-33.

10. Marks SJ, Merchant RC, Clark MA, et al. Potential healthcare insurance and provider barriers to preexposure prophylaxis utilization among young men who have sex with men. AIDS Patient Care STDS. 2017;31:470-8.

11. Siegler AJ, Mouhanna F, Giler RM, et al. The prevalence of pre-exposure prophylaxis use and the pre-exposure prophylaxis-to-need ratio in the fourth quarter of 2017, United States. Ann Epidemiol. 2018;28:841-9.

12. Centers for Disease Control and Prevention. HIV in the United States by region; 2018. https://www.cdc. gov/hiv/statistics/overview/geographicdistribution. html. Accessed 1 July 2019.

13. McMahan VM, Martin A, Garske L, et al. Development of a targeted educational intervention to increase pre-exposure prophylaxis uptake among cisgender men and transgender individuals who have sex with men and use methamphetamine in Seattle (WA, USA). Sex Health. 2019;16:139-47.

14. Louisiana HealthHub. What is the TelePrEP program? https://www.louisianahealthhub.org/ teleprep/. Accessed 15 Aug 2019.

15. Harawa NT, Bempong GA, Fields S, et al. Engaging black men who have sex with men (BMSM) in Los Angeles in HIV pre-exposure prophylaxis (PrEP). California HIV/AIDS Policy Centers; 2016.

16. Kwa S, Ma Y. Increase in willingness to take preexposure prophylaxis among men who have sex with men in Los Angeles, 2011 to 2014. Los Angeles County Department of Public Health Conference; 2015.

17. Galang RR, Mendoza MCB, Smith DK. HIV preexposure prophylaxis among U.S. adults: awareness of 
and willingness to recommend or take-HealthStyles Surveys, 2009-2014. J Prev Treat HIV/AIDS. 2017;2.

18. Storrow L, Montenegro J. Advancing HIV prevention through public opinion polling: lessons from the southern United States. 10th IAS Conference on HIV Science 2019, Mexico City.

19. Shende T, Fisher J, Perez-Velez C, et al. PrEP knowledge and attitudes among adults attending public health clinics in Southern Arizona. 10th IAS Conference on HIV Science 2019, Mexico City.

20. Gomar Ramirez C. Identifying and addressing barriers to pre-exposure prophylaxis initiation via telecommunication intervention in urban NYC. 10th IAS Conference on HIV Science 2019, Mexico City.

21. Farthing H, Rodriguez A, Armstrong M, et al. Discomfort discussing HIV/AIDS and lack of awareness are barriers to partner-to-partner pre-exposure prophylaxis education. Int J STD AIDS. 2019;30: 147-53.

22. Blumenthal J, Jain S, Krakower D, et al. Knowledge is power! Increased provider knowledge scores regarding pre-exposure prophylaxis (PrEP) are associated with higher rates of PrEP prescription and future intent to prescribe PrEP. AIDS Behav. 2015;19:802-10.

23. Zhang HL, Rhea SK, Hurt CB, et al. HIV preexposure prophylaxis implementation at local health departments: a statewide assessment of activities and barriers. J Acquir Immune Defic Syndr. 2018;77: 72-7.

24. Bagchi AD, Holzemer W. Support for PrEP among New Jersey health care workers. J Assoc Nurses AIDS Care. 2018;29:849-57.

25. Ellis M, Scroggins S, Shacham E, Moore K. Training, communication, and prescribing patterns of preexposure prophylaxis (PrEP) among a sample of nurse practitioners in the United States: important gaps and opportunities. 10th IAS Conference on HIV Science 2019, Mexico City.

26. Gunn LH, Janson B, Lorjuste I, Summers L, Burns P, Bryant $\mathrm{T}$ 3rd. Healthcare providers' knowledge, readiness, prescribing behaviors, and perceived barriers regarding routine HIV testing and pre-exposure prophylaxis in DeLand, Florida. SAGE Open Med. 2019;7:2050312119836030.

27. Wood BR, McMahan VM, Naismith K, Stockton JB, Delaney LA, Stekler JD. Knowledge, practices, and barriers to HIV preexposure prophylaxis prescribing among Washington State medical providers. Sex Transm Dis. 2018;45:452-8.
28. Ojile N, Sweet D, Kallail KJ. A preliminary study of the attitudes and barriers of family physicians to prescribing HIV preexposure prophylaxis. Kans J Med. 2017;10:40-2.

29. Hoffman S, Guidry JA, Collier KL, et al. A clinical home for preexposure prophylaxis: diverse health care providers' perspectives on the "purview paradox". J Int Assoc Provid AIDS Care. 2016;15:59-65.

30. Mayer KH, Allan-Blitz LT. PrEP 1.0 and beyond: optimizing a biobehavioral intervention. J Acquir Immune Defic Syndr. 2019;82(Suppl 2):S113-7.

31. Mullins TLK, Idoine CR, Zimet GD, Kahn JA. Primary care physician attitudes and intentions toward the use of HIV pre-exposure prophylaxis in adolescents in one metropolitan region. J Adolesc Health. 2019;64:581-8.

32. Gibas KM, van den Berg P, Powell VE, Krakower DS. Drug resistance during HIV pre-exposure prophylaxis. Drugs. 2019;79:609-19.

33. Centers for Disease Control and Prevention, US Public Health Service: preexposure prophylaxis for the prevention of HIV infection in the United States-2017 Update: a clinical practice guideline. https://www.cdc.gov/hiv/pdf/risk/prep/cdc-hivprep-guidelines-2017.pdf. Published March 2018; 2017.

34. Kwakwa HA, Bessias S, Sturgis D, et al. Attitudes toward HIV pre-exposure prophylaxis in a United States urban clinic population. AIDS Behav. 2016;20:1443-50.

35. Braksmajer A, Leblanc NM, El-Bassel N, Urban MA, McMahon JM. Feasibility and acceptability of preexposure prophylaxis use among women in violent relationships. AIDS Care. 2019;31:475-80.

36. Wendlandt R, Salazar LF, Mijares A, Pitts N. Genderbased violence and HIV risk among African American women: a qualitative study. J HIV AIDS Soc Serv. 2016;15:83-98.

37. Rutledge R, Madden L, Ogbuagu O, Meyer JP. HIV risk perception and eligibility for pre-exposure prophylaxis in women involved in the criminal justice system. AIDS Care. 2018;30:1282-9.

38. Fisher CB, Fried AL, Desmond M, Macapagal K, Mustanski B. Facilitators and barriers to participation in PrEP HIV prevention trials involving transgender male and female adolescents and emerging adults. AIDS Educ Prev. 2017;29:205-17.

39. Kahle EM, Sharma A, Sullivan SP, Stephenson R. HIV prioritization and risk perception among an online sample of men who have sex with men in 
the United States. Am J Mens Health. 2018;12: 676-87.

40. Oldenburg CE, Mitty JA, Biello KB, et al. Differences in attitudes about HIV pre-exposure prophylaxis use among stimulant versus alcohol using men who have sex with men. AIDS Behav. 2016;20:1451-60.

41. Remien RH, Stirratt MJ, Nguyen N, Robbins RN, Pala AN, Mellins CA. Mental health and HIV/AIDS: the need for an integrated response. AIDS. 2019;33: $1411-20$.

42. Blank MB, Himelhoch SS, Balaji AB, et al. A multisite study of the prevalence of HIV with rapid testing in mental health settings. Am J Public Health. 2014;104:2377-84.

43. Himelhoch S, Goldberg R, Calmes C, et al. Screening for and prevalence of HIV and hepatitis C among an outpatient urban sample of people with serious mental illness and co-occurring substance abuse. J Community Psychol. 2011;39:231-9.

44. Cornelius T, Jones M, Merly C, Welles B, Kalichman MO, Kalichman SC. Impact of food, housing, and transportation insecurity on ART adherence: a hierarchical resources approach. AIDS Care. 2017;29:449-57.

45. Flash CA, Dale SK, Krakower DS. Pre-exposure prophylaxis for HIV prevention in women: current perspectives. Int $\mathrm{J}$ Womens Health. 2017;9: 391-401.

46. Brinkley-Rubinstein L, Peterson M, Arnold T, et al. Knowledge, interest, and anticipated barriers of preexposure prophylaxis uptake and adherence among gay, bisexual, and men who have sex with men who are incarcerated. PLoS One. 2018;13:e0205593.

47. Gelberg L, Gallagher TC, Andersen RM, Koegel P. Competing priorities as a barrier to medical care among homeless adults in Los Angeles. Am J Public Health. 1997;87:217-20.

48. Carter GA, Jayawardene W, Agley J, et al. Development of a 10-item tool to identify advanced practice nurse readiness to prescribe pre-exposure prophylaxis. J Assoc Nurses AIDS Care. 2019;30:312-20.

49. Calabrese SK, Earnshaw VA, Underhill K, et al. Prevention paradox: medical students are less inclined to prescribe HIV pre-exposure prophylaxis for patients in highest need. J Int AIDS Soc. 2018;21: e25147.

50. Rael CT, Martinez M, Giguere R, et al. Barriers and facilitators to oral PrEP use among transgender women in New York City. AIDS Behav. 2018;22: 3627-36.
51. Dubov A, Galbo P Jr, Altice FL, Fraenkel L. Stigma and shame experiences by MSM who take PrEP for HIV prevention: a qualitative study. Am J Mens Health. 2018;12:1843-54.

52. Duran D. Truvada whores? 2012. https://www. huffpost.com/entry/truvada-whores_b_2113588.

Accessed 2 Sep 2019.

53. Blackstock OJ, Moore BA, Berkenblit GV, et al. A cross-sectional online survey of HIV pre-exposure prophylaxis adoption among primary care physicians. J Gen Intern Med. 2017;32:62-70.

54. Golub SA. PrEP stigma: implicit and explicit drivers of disparity. Curr HIV/AIDS Rep. 2018;15:190-7.

55. Karris MY, Beekmann SE, Mehta SR, Anderson CM, Polgreen PM. Are we prepped for preexposure prophylaxis (PrEP)? Provider opinions on the realworld use of PrEP in the United States and Canada. Clin Infect Dis. 2014;58:704-12.

56. Marcus JL, Katz KA, Krakower DS, Calabrese SK. Risk compensation and clinical decision making-the case of HIV preexposure prophylaxis. N Engl J Med. 2019;380:510-2.

57. Calabrese SK, Earnshaw VA, Underhill K, Hansen $\mathrm{NB}$, Dovidio JF. The impact of patient race on clinical decisions related to prescribing HIV preexposure prophylaxis (PrEP): assumptions about sexual risk compensation and implications for access. AIDS Behav. 2014;18:226-40.

58. Hall WJ, Chapman MV, Lee KM, et al. Implicit racial/ethnic bias among health care professionals and its influence on health care outcomes: a systematic review. Am J Public Health. 2015;105: e60-76.

59. Maina IW, Belton TD, Ginzberg S, Singh A, Johnson TJ. A decade of studying implicit racial/ethnic bias in healthcare providers using the implicit association test. Soc Sci Med. 2018;199:219-29.

60. Grant JM, Mottet LA, Tanis J, Harrison J, Herman JL, Keisling M. Injustice at every turn: a report of the national transgender discrimination survey; 2011. https://www.transequality.org/sites/default/files/ docs/resources/NTDS_Report.pdf. Accessed 11 Nov 2018.

61. Obermeyer Z, Powers B, Vogeli C, Mullainathan S. Dissecting racial bias in an algorithm used to manage the health of populations. Science. 2019;366: 447-53.

62. Auerbach JD, Kinsky S, Brown G, Charles V. Knowledge, attitudes, and likelihood of pre-exposure prophylaxis (PrEP) use among US women at 
risk of acquiring HIV. AIDS Patient Care STDS. 2015;29:102-10.

63. Scharff DP, Mathews KJ, Jackson P, Hoffsuemmer J, Martin E, Edwards D. More than Tuskegee: understanding mistrust about research participation. J Health Care Poor Underserved. 2010;21:879-97.

64. Kemet S. Insight medicine lacks-the continuing relevance of Henrietta Lacks. $\mathrm{N}$ Engl J Med. 2019;381:800-1.

65. Spector-Bagdady K, Lombardo PAUS. Public Health Service STD experiments in Guatemala (1946-1948) and their aftermath. Ethics Hum Res. 2019;41: 29-34.

66. Bogart LM, Thorburn S. Are HIV/AIDS conspiracy beliefs a barrier to HIV prevention among African Americans? J Acquir Immune Defic Syndr. 2005;38: 213-8.

67. Bogart LM, Wagner G, Galvan FH, Banks D. Conspiracy beliefs about HIV are related to antiretroviral treatment nonadherence among African American men with HIV. J Acquir Immune Defic Syndr. 2010;53:648-55.

68. Eaton LA, Kalichman SC, Price D, Finneran S, Allen A, Maksut J. Stigma and conspiracy beliefs related to pre-exposure prophylaxis (PrEP) and interest in using PrEP among black and white men and transgender women who have sex with men. AIDS Behav. 2017;21:1236-46.

69. Brooks RA, Allen VC Jr, Regan R, Mutchler MG, Cervantes-Tadeo R, Lee SJ. HIV/AIDS conspiracy beliefs and intention to adopt preexposure prophylaxis among black men who have sex with men in Los Angeles. Int J STD AIDS. 2018;29:375-81.

70. Olansky E, Mansergh G, Pitts N, et al. PrEP awareness in the context of HIV/AIDS conspiracy beliefs among black/African American and Hispanic/ Latino MSM in three urban US cities. J Homosex. 2019. https://doi.org/10.1080/00918369.2018. 1557953.

71. US Food and Drug Administration. Final report on the dialogues on diversifying clinical trials conference. $\quad$ https://www.fda.gov/media/84982/ download. Accessed 9 Oct 2019.

72. Andrasik MP, Chandler C, Powell B, et al. Bridging the divide: HIV prevention research and Black men who have sex with men. Am J Public Health. 2014;104:708-14.

73. Sevelius JM, Deutsch MB, Grant R. The future of PrEP among transgender women: the critical role of gender affirmation in research and clinical practices. J Int AIDS Soc. 2016;19:21105.
74. Greene GJ, Nery-Hurwit M, Matson M, Macapagal K. Perceived barriers to emerging PrEP modalities in the US: social determinants of health and modalityspecific attributes may inhibit PrEP uptake among sexual and gender minority adolescents. 10th IAS Conference on HIV Science 2019, Mexico City.

75. Felsher M, Szep Z, Krakower D, Martinez-Donate A, Tran N, Roth AM. "I don't need PrEP right now": a qualitative exploration of the barriers to PrEP care engagement through the application of the health belief model. AIDS Educ Prev. 2018;30:369-81.

76. Rice WS, Stringer KL, Sohail M, et al. Accessing preexposure prophylaxis (PrEP): perceptions of current and potential PrEP users in Birmingham, Alabama. AIDS Behav. 2019;23(11):2966-79.

77. Ojikutu BO, Bogart LM, Mayer KH, Stopka TJ, Sullivan PS, Ransome Y. Spatial access and willingness to use pre-exposure prophylaxis among black/African American individuals in the United States: cross-sectional survey. JMIR Public Health Surveill. 2019;5:e12405.

78. Roth AM, Aumaier BL, Felsher MA, et al. An exploration of factors impacting preexposure prophylaxis eligibility and access among syringe exchange users. Sex Transm Dis. 2018;45:217-21.

79. Hubach RD, Currin JM, Sanders CA, et al. Barriers to access and adoption of pre-exposure prophylaxis for the prevention of HIV among men who have sex with men (MSM) in a relatively rural state. AIDS Educ Prev. 2017;29:315-29.

80. Doblecki-Lewis S, Butts S, Botero V, Klose K, Cardenas $G$, Feaster D. A randomized study of passive versus active PrEP patient navigation for a heterogeneous population at risk for HIV in South Florida. J Int Assoc Provid AIDS Care. 2019;18: 2325958219848848.

81. Park CJ, Taylor TN, Gutierrez NR, Zingman BS, Blackstock OJ. Pathways to HIV pre-exposure prophylaxis among women prescribed PrEP at an urban sexual health clinic. J Assoc Nurses AIDS Care. 2019;30:321-9.

82. Siegler AJ, Bratcher A, Weiss KM, Mouhanna F, Ahlschlager L, Sullivan PS. Location location location: an exploration of disparities in access to publicly listed pre-exposure prophylaxis clinics in the United States. Ann Epidemiol. 2018;28:858-64.

83. Bazzi A, Childs E, Valente $\mathrm{P}$, et al. Challenges implementing pre-exposure prophylaxis (PrEP) for people who inject drugs in non-urban areas of the United States. 10th IAS Conference on HIV Science 2019, Mexico City. 
84. Biello KB, Bazzi AR, Mimiaga MJ, et al. Perspectives on HIV pre-exposure prophylaxis (PrEP) utilization and related intervention needs among people who inject drugs. Harm Reduct J. 2018;15:55.

85. Kolata G. Facing legal action, insurer now will cover people taking Truvada, an H.I.V.-prevention drug; $2019 . \quad$ https://www.nytimes.com/2019/01/10/ health/hiv-aids-truvada-insurance.html. Accessed 7 Jan 2020.

86. Sax P. A urologist, PrEP, and discriminatory disability insurance practices: Dr. Paul Sax interviews Dr. Philip Cheng. Open Forum Infect Dis. 2018;5: ofy149-ofy.

87. Lee R. Publix grocery chain denies PrEP coverage to its employees; 2018. https://www.thebody.com/ content/80784/publix-grocery-chain-denies-prepcoverage-to-its-e.html. Accessed 7 Jan 2020.

88. Calabrese SK, Magnus M, Mayer KH, et al. Putting PrEP into practice: lessons learned from earlyadopting U.S. providers' firsthand experiences providing HIV pre-exposure prophylaxis and associated care. PLoS One. 2016;11:e0157324.

89. Sevelius JM, Keatley J, Calma N, Arnold E. 'I am not a man': trans-specific barriers and facilitators to PrEP acceptability among transgender women. Glob Public Health. 2016;11:1060-75.

90. Rowniak S, Ong-Flaherty C, Selix N, Kowell N. Attitudes, beliefs, and barriers to PrEP among trans men. AIDS Educ Prev. 2017;29:302-14.

91. Poteat T, Wirtz A, Malik M, et al. A gap between willingness and uptake: findings from mixed methods research on HIV prevention among black and Latina transgender women. J Acquir Immune Defic Syndr. 2019;82:131-40.

92. Blum C. Talking about PrEP and HIV treatment in a time of class action lawsuits; 2019. https://www. positivelyaware.com/articles/truvada-safety. Accessed 10 Oct 2019.

93. Adrover C, Bodnar T, Huang Z, Telenti A, Salathé M. Identifying adverse effects of HIV drug treatment and associated sentiments using Twitter. JMIR Public Health Surveill. 2015;1:e7.

94. Kakalou C, Lazarus JV, Koutkias V. Mining social media for perceptions and trends on HIV pre-exposure prophylaxis. Stud Health Technol Inform. 2019;264:959-63.

95. Hill BS, Patel VV, Haughton LJ, Blackstock OJ. Leveraging social media to explore black women's perspectives on HIV pre-exposure prophylaxis. J Assoc Nurses AIDS Care. 2018;29:107-14.
96. Mimiaga MJ, White JM, Krakower DS, Biello KB, Mayer KH. Suboptimal awareness and comprehension of published preexposure prophylaxis efficacy results among physicians in Massachusetts. AIDS Care. 2014;26:684-93.

97. Puro V, Palummieri A, De Carli G, Piselli P, Ippolito G. Attitude towards antiretroviral pre-exposure prophylaxis (PrEP) prescription among HIV specialists. BMC Infect Dis. 2013;13:217.

98. Newman R, Katchi T, Karass M, et al. Enhancing HIV pre-exposure prophylaxis practices via an educational intervention. Am J Ther. 2019;26:e462-8.

99. Coy KC, Hazen RJ, Kirkham HS, Delpino A, Siegler AJ. Persistence on HIV preexposure prophylaxis medication over a 2-year period among a national sample of 7148 PrEP users, United States, 2015 to 2017. J Int AIDS Soc. 2019;22:e25252.

100. Choopanya K, Martin M, Suntharasamai P, et al. Antiretroviral prophylaxis for HIV infection in injecting drug users in Bangkok, Thailand (the Bangkok Tenofovir Study): a randomised, doubleblind, placebo-controlled phase 3 trial. Lancet. 2013;381:2083-90.

101. Thigpen MC, Kebaabetswe PM, Paxton LA, et al. Antiretroviral preexposure prophylaxis for heterosexual HIV transmission in Botswana. N Engl J Med. 2012;367:423-34.

102. Pinto RM, Berringer KR, Melendez R, Mmeje O. Improving PrEP implementation through multilevel interventions: a synthesis of the literature. AIDS Behav. 2018;22:3681-91.

103. Adams JL, Shelley K, Nicol MR. Review of real-world implementation data on emtricitabine-tenofovir disoproxil fumarate as HIV pre-exposure prophylaxis in the United States. Pharmacotherapy. 2019;39:486-500.

104. Mayer KH, Chan PA, Patel R, Flash CA, Krakower DS. Evolving models and ongoing challenges for HIV preexposure prophylaxis implementation in the United States. J Acquir Immune Defic Syndr. 2018;77:119-27.

105. Koechlin FM, Fonner VA, Dalglish SL, et al. Values and preferences on the use of oral pre-exposure prophylaxis (PrEP) for HIV prevention among multiple populations: a systematic review of the literature. AIDS Behav. 2017;21:1325-35.

106. Hannaford A, Lipshie-Williams M, Starrels JL, et al. The use of online posts to identify barriers to and facilitators of HIV pre-exposure prophylaxis (PrEP) among men who have sex with men: a comparison to a systematic review of the peer-reviewed literature. AIDS Behav. 2018;22:1080-95. 
107. Peng P, Su S, Fairley CK, et al. A global estimate of the acceptability of pre-exposure prophylaxis for HIV among men who have sex with men: a systematic review and meta-analysis. AIDS Behav. 2018;22:1063-74.

108. Scholl E. Improving outpatient implementation of preexposure prophylaxis in men who have sex with men. J Am Assoc Nurse Pract. 2016;28:446-52.

109. Vaitses Fontanari AM, Zanella GI, Feijo M, Churchill S, Rodrigues Lobato MI, Costa AB. HIVrelated care for transgender people: a systematic review of studies from around the world. Soc Sci Med. 2019;230:280-94.

110. Pacifico de Carvalho N, Mendicino CCP, Candido RCF, Alecrim DJD, Menezes de Padua CA. HIV preexposure prophylaxis (PrEP) awareness and acceptability among trans women: a review. AIDS Care. 2019;31:1234-40.

111. Chapman Lambert C, Marrazzo J, Amico KR, Mugavero MJ, Elopre L. PrEParing women to prevent HIV: an integrated theoretical framework to PrEP black women in the United States. J Assoc Nurses AIDS Care. 2018;29:835-48.

112. Bradley E, Forsberg K, Betts JE, et al. Factors affecting pre-exposure prophylaxis implementation for women in the United States: a systematic review. J Womens Health (Larchmt). 2019;28:1272-85.

113. Raifman J, Nunn A, Oldenburg CE, et al. An evaluation of a clinical pre-exposure prophylaxis education intervention among men who have sex with men. Health Serv Res. 2018;53:2249-67.

114. Hygiene NYCDoHaM. Learn about HIV and AIDS; $2019 . \quad$ https://www1.nyc.gov/site/doh/health/ health-topics/aids-hiv.page. Accessed 2 Sep 2019.

115. The National LGBT Health Education Center. https://fenwayhealth.org/the-fenway-institute/ education/the-national-lgbt-health-educationcenter/. Accessed 11 Nov 2019.

116. Dehlin JM, Stillwagon R, Pickett J, Keene L, Schneider JA. \#PrEP4Love: an evaluation of a sex-positive HIV prevention campaign. JMIR Public Health Surveill. 2019;5:e12822.

117. Sophus AI, Mitchell JW. A review of approaches used to increase awareness of pre-exposure prophylaxis (PrEP) in the United States. AIDS Behav. 2019;23:1749-70.

118. Patel VV, Ginsburg Z, Golub SA, et al. Empowering with PrEP (E-PrEP), a peer-led social media-based intervention to facilitate HIV preexposure prophylaxis adoption among young black and Latinx gay and bisexual men: protocol for a cluster randomized controlled trial. JMIR Res Protoc. 2018;7:e11375.

119. Wade Taylor S, Mayer KH, Elsesser SM, Mimiaga MJ, O'Cleirigh C, Safren SA. Optimizing content for preexposure prophylaxis (PrEP) counseling for men who have sex with men: perspectives of PrEP users and high-risk PrEP naive men. AIDS Behav. 2014;18: 871-9.

120. Shaeer KM, Sherman EM, Shafiq S, Hardigan P. Exploratory survey of Florida pharmacists' experience, knowledge, and perception of HIV pre-exposure prophylaxis. J Am Pharm Assoc. 2014;54: $610-7$.

121. Traeger MW, Cornelisse VJ, Asselin J, et al. Association of HIV preexposure prophylaxis with incidence of sexually transmitted infections among individuals at high risk of HIV infection. JAMA. 2019;321:1380-90.

122. Mayer KH, Maloney KM, Levine K, et al. Sociodemographic and clinical factors associated with increasing bacterial sexually transmitted infection diagnoses in men who have sex with men accessing care at a Boston community health center (2005-2015). Open Forum Infect Dis. 2017;4: ofx 214

123. Newcomb ME, Moran K, Feinstein BA, Forscher E, Mustanski B. Pre-exposure prophylaxis (PrEP) use and condomless anal sex: evidence of risk compensation in a cohort of young men who have sex with men. J Acquir Immune Defic Syndr. 2018;77: 358-64.

124. Ong JJ, Baggaley RC, Wi TE, et al. Global epidemiologic characteristics of sexually transmitted infections among individuals using preexposure prophylaxis for the prevention of HIV infection: a systematic review and meta-analysis. JAMA Netw Open. 2019;2:e1917134.

125. McCormack S, Dunn DT, Desai M, et al. Pre-exposure prophylaxis to prevent the acquisition of HIV-1 infection (PROUD): effectiveness results from the pilot phase of a pragmatic open-label randomised trial. Lancet. 2016;387:53-60.

126. Hare CB, Coll J, Ruane $\mathrm{P}$, et al. The phase 3 DISCOVER study: daily F/TAF or F/TDF for HIV preexposure prophylaxis [Abstract]. Conference on retroviruses and opportunistic infections, Seattle; 2019.

127. Fonner VA, Dalglish SL, Kennedy CE, et al. Effectiveness and safety of oral HIV preexposure prophylaxis for all populations. AIDS. 2016;30: 1973-83. 
128. Okwundu CI, Uthman OA, Okoromah CA. Antiretroviral pre-exposure prophylaxis (PrEP) for preventing HIV in high-risk individuals. Cochrane Database Syst Rev. 2012;7:CD007189.

129. Rojas Castro D, Delabre RM, Molina JM. Give PrEP a chance: moving on from the "risk compensation" concept. J Int AIDS Soc. 2019;22(Suppl 6):e25351.

130. Quaife M, MacGregor L, Ong JJ, et al. Risk compensation and STI incidence in PrEP programmes. Lancet HIV. 2019. https://doi.org/10.1016/S23523018(19)30333-9.

131. Volk JE, Nguyen DP, Hare CB, Marcus JL. HIV infection and drug resistance with unsupervised use of HIV pre-exposure prophylaxis. AIDS Res Hum Retroviruses. 2018;34:329-30.

132. World Health Organization, WHO Implementation tool for pre-exposure prophylaxis (PrEP) of HIV infection. Module 1: clinical. Geneva: World Health Organization; 2017 (WHO/HIV/2017.17). Licence: CC BY-NC-SA 3.0 IGO.

133. Highleyman L. US Preventive Services Task Force press release; 2019. https://www.poz.com/article/ preventive-services-task-force-recommends-prephiv-prevention. Accessed 15 Aug 2019.

134. US Preventive Services Task Force. Preexposure prophylaxis for the prevention of HIV infection: US Preventive Services Task Force recommendation statement. JAMA. 2019;321:2203-13.

135. Calabrese SK, Underhill K. How stigma surrounding the use of HIV preexposure prophylaxis undermines prevention and pleasure: a call to destigmatize "Truvada whores". Am J Public Health. 2015;105: 1960-4.

136. Liu AY, Coleman K, VIttinghoff E, et al. Assessing the PrEP continuum in the San Francisco Bay area: the quickie mobile survey. Conference on retroviruses and opportunistic infections, Seattle; 2019.

137. Underhill K, Morrow KM, Colleran CM, et al. Access to healthcare, HIV/STI testing, and preferred preexposure prophylaxis providers among men who have sex with men and men who engage in streetbased sex work in the US. PLoS One. 2014;9: e112425.

138. Kelen GD, Rothman RE. Emergency departmentbased HIV testing: too little, but not too late. Ann Emerg Med. 2009;54:65-71.

139. Kelley-Ross Pharmacy Group. One-step PrEP. https://www.kelley-ross.com/polyclinic/prep/. Accessed 2 Sep 2019.
140. Tung E, Thomas A, Eichner A, Shalit P. Feasibility of a pharmacist-run HIV PrEP clinic in a community pharmacy setting. Conference on retroviruses and opportunistic infections, Boston; 2017.

141. Tung EL, Thomas A, Eichner A, Shalit P. Implementation of a community pharmacy-based preexposure prophylaxis service: a novel model for preexposure prophylaxis care. Sex Health. 2018;15: 556-61.

142. World Health Organization. Serving the needs of key populations: case examples of innovation and good practice in HIV prevention, diagnosis, treatment and care; 2017. https://www.who.int/hiv/ pub/populations/key-populations-case-examples/ en/. Accessed 7 Jan 2020.

143. Iowa TelePrEP. TelePrEP. https://www.prepiowa. org/teleprep. Accessed 15 Aug 2019.

144. Siegler AJ, Mayer KH, Liu AY, et al. Developing and assessing the feasibility of a home-based preexposure prophylaxis monitoring and support program. Clin Infect Dis. 2019;68:501-4.

145. Vaidya A, Malebranche D, Cantos D, Lora M. Reframing PrEP: design and implementation of a dynamic, health-focused, pharmacy-based PrEP program in a large county hospital system in the Southeast US. APHA 2019 Annual Meeting and Expo 2019, Philadelphia.

146. Smith DK, Van Handel M, Huggins R. Estimated coverage to address financial barriers to HIV preexposure prophylaxis among persons with indications for its use, United States, 2015. J Acquir Immune Defic Syndr. 2017;76:465-72.

147. What is 'Ending the HIV epidemic: a plan for America'? https://www.hiv.gov/federal-response/ ending-the-hiv-epidemic/overview. Accessed 11 Nov 2019.

148. Khalili J, Landovitz RJ. HIV preexposure prophylaxis - the role of primary care clinicians in ending the HIV epidemic. JAMA Intern Med. 2019;180: 126-30.

149. Rosenberg J. Harris introduces Bill that would require all insurance plans to cover PrEP and related services; 2019. https://www.ajmc.com/newsroom/ harris-introduces-bill-that-would-require-allinsurance-plans-to-cover-prep-and-related-services. Accessed 7 Jan 2020.

150. Pre-exposure prophylaxis assistance program (PrEPAP). https://www.health.ny.gov/diseases/aids/ general/resources/adap/prep.htm. Accessed 2 Sep 2019. 
151. Pre-exposure prophylaxis drug assistance program (PrEP DAP). https://www.doh.wa.gov/ YouandYourFamily/IllnessandDisease/HIV/ Prevention/PrEPDAP. Accessed 2 Sep 2019.

152. Pre-exposure prophylaxis (PrEP). https://www. sfcityclinic.org/services/hiv-prevention-care/prep. Accessed 2 Sep 2019.

153. Washington State Department of Health. Pre-exposure prophylaxis drug assistance program (PrEP DAP). https://www.doh.wa.gov/ YouandYourFamily/IllnessandDisease/HIV/ Prevention/PrEPDAP. Accessed 9 Oct 2019.

154. Malcolm N, Marx K, Hart J, et al. Decision-making guide for the provision of PrEP services in Title X-funded family planning service sites. Rockville: U.S. Department of Health and Human Services, Office of Population Affairs; 2019.

155. Eaton LA, Matthews DD, Driffin DD, et al. A multiUS city assessment of awareness and uptake of preexposure prophylaxis (PrEP) for HIV prevention among black men and transgender women who have sex with men. Prev Sci. 2017;18:505-16.

156. Garnett M, Hirsch-Moverman Y, Franks J, HayesLarson E, El-Sadr WM, Mannheimer S. Limited awareness of pre-exposure prophylaxis among black men who have sex with men and transgender women in New York city. AIDS Care. 2018;30:9-17.

157. Sales JM, Cwiak C, Haddad LB, et al. Brief report: impact of PrEP training for family planning providers on HIV prevention counseling and patient interest in PrEP in Atlanta, Georgia. J Acquir Immune Defic Syndr. 2019;81:414-8.

158. Patel AS, Goparaju L, Sales JM, et al. Brief report: PrEP eligibility among at-risk women in the Southern United States: associated factors, awareness, and acceptability. J Acquir Immune Defic Syndr. 2019;80:527-32.

159. Hirschhorn L, Brown R, Friedman EE, et al. Women's PrEP knowledge, attitudes, preferences and experience in Chicago. Conference on retroviruses and opportunistic infections, Seattle; 2019.

160. Reisner SL, Moore CS, Asquith A, et al. High risk and low uptake of pre-exposure prophylaxis to prevent HIV acquisition in a national online sample of transgender men who have sex with men in the United States. J Int AIDS Soc. 2019;22:e25391.

161. Marcus JL, Hurley LB, Dentoni-Lasofsky D, et al. Barriers to preexposure prophylaxis use among individuals with recently acquired HIV infection in Northern California. AIDS Care. 2019;31:536-44.
162. Ojikutu BO, Bogart LM, Higgins-Biddle M, et al. Facilitators and barriers to pre-exposure prophylaxis (PrEP) use among black individuals in the United States: results from the National Survey on HIV in the Black Community (NSHBC). AIDS Behav. 2018;22:3576-87.

163. Finlayson T, Cha S, Denson D, et al. Changes in HIV PrEP awareness and use among men who have sex with men, 2014 vs 2017. Conference on retroviruses and opportunistic infections, Seattle; 2019.

164. Restar AJ, Kuhns L, Reisner SL, Ogunbajo A, Garofalo R, Mimiaga MJ. Acceptability of antiretroviral pre-exposure prophylaxis from a cohort of sexually experienced young transgender women in two U.S. cities. AIDS Behav. 2018;22:3649-57.

165. Santa Maria D, Gallardo KR, Narendorf S, et al. Implications for PrEP uptake in young adults experiencing homelessness: a mixed methods study. AIDS Educ Prev. 2019;31:63-81.

166. Melhado T, Salami T, Olutoye O, Allison W. Perceptions of HIV risk and knowledge of HIV prevention strategies among young minorities recently diagnosed with HIV infection in South Texas, Unites States (U.S.). 10th IAS Conference on HIV Science, Mexico City; 2019.

167. Cahill S, Taylor SW, Elsesser SA, Mena L, Hickson D, Mayer KH. Stigma, medical mistrust, and perceived racism may affect PrEP awareness and uptake in black compared to white gay and bisexual men in Jackson, Mississippi and Boston, Massachusetts. AIDS Care. 2017;29:1351-8.

168. Bunting S, Saqueton R, Batteson T. Leveraging interprofessional student collaboration to educate healthcare providers and increase access to pre-exposure prophylaxis: results of a novel educational approach. 10th IAS Conference on HIV science, Mexico City; 2019.

169. Blumenthal J, Jain S, Mulvihill E, et al. Perceived versus calculated HIV risk: implications for pre-exposure prophylaxis uptake in a randomized trial of men who have sex with men. J Acquir Immune Defic Syndr. 2019;80:e23-9.

170. Biello KB, Edeza A, Montgomery MC, Almonte A, Chan PA. Risk perception and interest in HIV preexposure prophylaxis among men who have sex with men with rectal gonorrhea and chlamydia infection. Arch Sex Behav. 2019;48:1185-90.

171. Mansergh G, Sullivan P, Hirshfield S, Stephenson R. Assessing sexual event-level substance use and risk behavior for HIV infection in a diverse sample of HIV-negative MSM in the era of PrEP, 2018. 10th IAS Conference on HIV science, Mexico City; 2019. 
172. Carley T, Siewert E, Naresh A. Interest in pre-exposure prophylaxis (PrEP) for HIV is limited among women in a general obstetrics and gynecology setting. AIDS Behav. 2019;23(10):2741-8.

173. Philbin MM, Parish C, Kinnard EN, et al. Women's perceived barriers and facilitators towards long-acting injectable pre-exposure prophylaxis (PrEP): results from six cities across the United States. 10th IAS Conference on HIV science, Mexico City; 2019.

174. Brooks RA, Nieto O, Landrian A, Fehrenbacher A, Cabral A. Experiences of pre-exposure prophylaxis (PrEP)-related stigma among black MSM PrEP users in Los Angeles. J Urban Health. 2019. https://doi. org/10.1007/s11524-019-00371-3.

175. Thomann M, Grosso A, Zapata R, Chiasson MA. 'WTF is PrEP?': attitudes towards pre-exposure prophylaxis among men who have sex with men and transgender women in New York City. Cult Health Sex. 2018;20:772-86.

176. Biello KB, Hosek S, Drucker MT, et al. Preferences for injectable PrEP among young U.S. cisgender men and transgender women and men who have sex with men. Arch Sex Behav. 2018;47:2101-7.

177. Jackman K-M, Kane J, Murray S, et al. Predictors of anticipated healthcare stigma among adult men who have sex with men in the United States and across sub-Saharan African countries. 10th IAS Conference on HIV science, Mexico City; 2019.

178. Calabrese SK, Dovidio JF, Tekeste M, et al. HIV preexposure prophylaxis stigma as a multidimensional barrier to uptake among women who attend planned parenthood. J Acquir Immune Defic Syndr. 2018;79:46-53.

179. Cyrus E, Villalba K, Jean-Gilles M, et al. Barriers and facilitators of PrEP use: a synthesis of proceedings of the Empowering Women's Health Summit, Miami, FL, 2018. 10th IAS conference on HIV science, Mexico City; 2019.

180. Blumenthal J, Morris S, Jain S, et al. HIV risk and characteristics of women seeking PrEP in a US demonstration project. Conference on retroviruses and opportunistic infections, Seattle; 2019.

181. Holloway IW, Tan D, Gildner JL, et al. Facilitators and barriers to pre-exposure prophylaxis willingness among young men who have sex with men who use geosocial networking applications in California. AIDS Patient Care STDS. 2017;31:517-27.

182. Flores D, Meanley S, Bauermeister J. Family characteristics in sex communication and social support: implications for emerging adult men who have sex with men's PrEP engagement. 10th IAS conference on HIV science, Mexico City; 2019.
183. Meanley S, Magnus M, Connochie D, Bauermeister JA. Indications for PrEP and engagement along the PrEP continuum among emerging adult men who have sex with men in the Mid-Atlantic United States. 10th IAS Conference on HIV science, Mexico City; 2019.

184. Matson M, Nery-Hurwit M, Jozsa K, Greene G, Macapagal K. Knowledge about pre-exposure prophylaxis (PrEP) among sexual and gender minority (SGM) adolescents assigned male at birth in the United States (US). 10th IAS Conference on HIV Science, Mexico City; 2019.

185. Reif S, Wilson E, McAllaster C. Perceptions and impact of HIV stigma among high risk populations in the US Deep South. J HIV AIDS. 2018. https://doi. org/10.16966/2380-5536.154.

186. Crawford N, Chamberlain A, Onwubiko U, Josma D, Morris J. Willingness to screen for pre-exposure prophylaxis in pharmacies among men who have sex with men. 10th IAS conference on HIV science, Mexico City; 2019.

187. Peterson M, Nowotny K, Dauria E, Arnold T, Brinkley-Rubinstein L. Institutional distrust among gay, bisexual, and other men who have sex with men as a barrier to accessing pre-exposure prophylaxis (PrEP). AIDS Care. 2019;31:364-9.

188. Maksut JL, Eaton LA, Siembida EJ, Fabius CD, Bradley AM. Health care discrimination, sex behavior disclosure, and awareness of pre-exposure prophylaxis among black men who have sex with men. Stigma Health. 2018;3:330-7.

189. Quinn K, Dickson-Gomez J, Zarwell M, Pearson B, Lewis M. "A gay man and a doctor are just like, a recipe for destruction": how racism and homonegativity in healthcare settings influence PrEP uptake among young black MSM. AIDS Behav. 2019;23: 1951-63.

190. Tekeste M, Hull S, Dovidio JF, et al. Differences in medical mistrust between Black and white women: implications for patient-provider communication about PrEP. AIDS Behav. 2019;23:1737-48.

191. Jaiswal J, Griffin M, Singer SN, et al. Structural barriers to pre-exposure prophylaxis use among young sexual minority men: the P18 cohort study. Curr HIV Res. 2018;16:237-49.

192. Jain JP, Strathdee SA, Patterson TL, et al. Perceived barriers to pre-exposure prophylaxis use and the role of syndemic factors among female sex workers in the Mexico-United States border region: a latent class analysis. AIDS Care. 2019. https://doi.org/10. 1080/09540121.2019.1626338. 